\title{
The Meridional Shift of the Midlatitude Westerlies over Arid Central Asia during the Past 21000 Years Based on the TraCE-21ka Simulations ${ }^{\circ}$
}

\author{
NANXUAN JIANG \\ Nansen-Zhu International Research Centre, Institute of Atmospheric Physics, Chinese Academy of Sciences, and University \\ of Chinese Academy of Sciences, Beijing, China \\ QING YAN \\ Nansen-Zhu International Research Centre, Institute of Atmospheric Physics, Chinese Academy of Sciences, Beijing, and Key \\ Laboratory of Meteorological Disaster/Collaborative Innovation Center on Forecast and Evaluation of Meteorological \\ Disasters, Nanjing University of Information Science and Technology, Nanjing, China \\ ZHIQING XU \\ Climate Change Research Center, Institute of Atmospheric Physics, Chinese Academy of Sciences, Beijing, China \\ JIAN SHI \\ Key Laboratory of Meteorological Disaster/Collaborative Innovation Center on Forecast and Evaluation of Meteorological \\ Disasters, Nanjing University of Information Science and Technology, Nanjing, China \\ RAN ZHANG \\ Climate Change Research Center, Institute of Atmospheric Physics, Chinese Academy of Sciences, Beijing, China
}

(Manuscript received 25 October 2019, in final form 6 June 2020)

\begin{abstract}
To advance our knowledge of the response of midlatitude westerlies to various external forcings, we investigate the meridional shift of midlatitude westerlies over arid central Asia (ACA) during the past 21000 years, which experienced more varied forcings than the present day based on a set of transient simulations. Our results suggest that the evolution of midlatitude westerlies over ACA and driving factors vary with time and across seasons. In spring, the location of midlatitude westerlies over ACA oscillates largely during the last deglaciation, driven by meltwater fluxes and continental ice sheets, and then shows a long-term equatorward shift during the Holocene controlled by orbital insolation. In summer, orbital insolation dominates the meridional shift of midlatitude westerlies, with poleward and equatorward migration during the last deglaciation and the Holocene, respectively. From a thermodynamic perspective, variations in zonal winds are linked with the meridional temperature gradient based on the thermal wind relationship. From a dynamic perspective, variations in midlatitude westerlies are mainly induced by anomalous sea surface temperatures over the Indian Ocean through the Matsuno-Gill response and over the North Atlantic Ocean by the propagation of Rossby waves, or both, but their relative importance varies across forcings. Additionally, the modeled meridional shift of midlatitude westerlies is broadly consistent with geological evidence, although model-data discrepancies still exist. Overall, our study provides a possible scenario for a meridional shift of midlatitude westerlies over ACA in response to various external forcings during the past 21000 years and highlights important roles of both the Indian Ocean and the North Atlantic Ocean in regulating Asian westerlies, which may shed light on the behavior of westerlies in the future.
\end{abstract}

Supplemental information related to this paper is available at the Journals Online website: https://doi.org/10.1175/JCLI-D-190798.s1.

Corresponding author: Qing Yan, yanqing@mail.iap.ac.cn

DOI: 10.1175/JCLI-D-19-0798.1

(C) 2020 American Meteorological Society. For information regarding reuse of this content and general copyright information, consult the AMS Copyright Policy (www.ametsoc.org/PUBSReuseLicenses). 


\section{Introduction}

Arid central Asia (ACA) $\left(25^{\circ}-55^{\circ} \mathrm{N}, 50^{\circ}-80^{\circ} \mathrm{E}\right)$ is one of the largest arid regions in the world. Water resources, biodiversity, and the livelihoods of people in such arid regions are highly influenced by precipitation variations (Huang et al. 2017, 2015; Wei et al. 2019). The spatiotemporal variation in precipitation over ACA is largely regulated by the midlatitude westerlies (Chen et al. 2019; Huang et al. 2013), which influence the water vapor transported into ACA from upstream (e.g., the North Atlantic Ocean) and the Indian Ocean (Chen et al. 2018; Mason and Goddard 2001). Previous studies suggested that a poleward shift of the midlatitude westerlies over ACA leads to reduced precipitation over the majority of ACA by inducing anomalous descending motion and vice versa for the equatorward shift (Zhao et al. 2018). Under the background of global warming, the midlatitude westerlies over ACA have moved equatorward since the 1970s and are projected to shift more equatorward in the twenty-first century, which generally leads to enhanced precipitation (Zhao et al. 2018). However, future projections from the present day only take the increased greenhouse gases and aerosol changes into consideration, neglecting several other potential forcings. At a longer time scale, warming induced by increased greenhouse gases will cause the melting of ice sheets, increasing the meltwater fluxes and altering the Atlantic overturning circulation, thereby indicating the nonnegligible role of ice sheets and meltwater fluxes in regulating the global climate (Golledge et al. 2019). Moreover, the increased (decreased) summer insolation corresponding to the warming (cooling) of the Northern Hemisphere indicates that orbital insolation is also an important factor in driving global climate change on the millennial time scale. To advance our knowledge on the response of the midlatitude westerlies over ACA to various external forcings and to improve our understanding of their future evolution, we should look back into Earth's history to explore the behavior of the midlatitude westerlies over ACA in the past.

The climate evolution during the past 21000 years (21 ka) was primarily forced by varying orbital insolation, greenhouse gases, meltwater fluxes, and continental ice sheets. This period provides an opportunity to examine how the midlatitude westerlies may respond to more varied external forcings than those of the present day and to place the westerlies' current behavior in a longterm paleoclimate context (He 2011; He et al. 2013). The midlatitude westerlies over ACA have exhibited remarkable changes during the past $21 \mathrm{ka}$. An et al. (2012) indicated that the westerlies strengthened during the Heinrich Stadial 1 (HS1; $17 \mathrm{ka}$ ) and the Younger Dryas (YD; $\sim 12 \mathrm{ka}$ ) and weakened during the BøllingAllerød interstadial period (BA; $\sim 14.5 \mathrm{ka}$ ) based on sediments from Qinghai Lake. This finding is confirmed by the loess sequence from Tacheng and Yumin ( $\mathrm{Li}$ et al. 2019), although the timings of their peaks differ. Moreover, Jia et al. (2018) deduced that the westerlies were the weakest during the last deglaciation and the early Holocene (16-6 ka), strongest during the mid-Holocene (6-3.1 ka), and moderate during the late Holocene (3.1-0 ka) according to moisture proxies. Geological evidence helps us better understand the past change in the midlatitude westerlies, but the possible mechanisms behind the reconstructions remain elusive.

Numerical simulation is suggested to be an efficient tool in revealing the response of climate to various external forcings and associated dynamic mechanisms. Based on phase 3 of the Paleoclimate Modeling Intercomparison Project, Wang et al. (2018) indicated that the annual westerly jet over the Northern Hemisphere at $200 \mathrm{hPa}$ experienced a poleward shift during the Last Glacial Maximum (LGM; 21 ka) due to the equatorward relative decreased meridional temperature gradient. Bromwich et al. (2004) suggested that the winter westerlies at $500 \mathrm{hPa}$ over North America were split into northern and southern branches by the large ice sheets (e.g., the Laurentide ice sheets) during the LGM. Toggweiler et al. (2006) pointed out that during the past $12 \mathrm{ka}$, the westerlies shifted poleward (equatorward) due to tropospheric warming (cooling) with higher (lower) $\mathrm{CO}_{2}$. In addition, Kong et al. (2017) concluded that the increased insolation in summer over the Northern Hemisphere could cause the poleward relative increased meridional temperature gradient and transient eddies and hence poleward-shifted westerlies.

Although these modeling studies proposed potential mechanisms for the meridional shift of the westerlies in past climates and highlighted important roles of the ice sheets, greenhouse gases, and orbital insolation in regulating the midlatitude westerlies, several issues are still worthy of further investigation. Notably, precipitation over ACA is concentrated in spring in its southwest part and in summer in its northeast part (Chen et al. 2011). However, previous studies have mainly focused on the Northern Hemisphere westerlies in summer. Variations in the midlatitude westerlies over ACA and their seasonal differences during the past 21 ka remain unknown. Furthermore, the respective impacts of various external forcings (i.e., orbital insolation, greenhouse gases, meltwater fluxes, and continental ice sheets) on the meridional shift of the midlatitude westerlies have not been 
systematically evaluated in existing modeling studies. Additionally, from the dynamic perspective, the midlatitude westerlies over ACA in the modern climate are generally considered to be regulated by anomalous sea surface temperatures (SSTs) in the North Atlantic (Chen et al. 2008; Mason and Goddard 2001), but several studies have highlighted the important role of the Indian Ocean (Chen et al. 2018; Zhao et al. 2018). Thus, it is meaningful to explore the relative importance of the North Atlantic Ocean and the Indian Ocean in altering the behavior of the midlatitude westerlies over ACA during the past $21 \mathrm{ka}$. Here, using a simulation of Transient Climate Evolution over the past 21000 years (TraCE-21ka), we attempt to address the following three questions: 1) How did the midlatitude westerlies over ACA vary during the past 21 $\mathrm{ka}$ in different seasons? 2) What are the dominant driving factors for the meridional shift of the midlatitude westerlies? 3) What is the relative importance of the North Atlantic and Indian Oceans in forming the anomalous atmospheric circulation over ACA and thereby the variation in the midlatitude westerlies? Answering these questions may advance our knowledge of the response of the midlatitude westerlies over ACA to different external factors and shed light on their behavior in the present and future.

The remainder of this paper is organized as follows. In section 2 , we present the data and methods utilized in this study and evaluate the performance of TraCE-21ka in reproducing the observed zonal winds over ACA in spring and summer. The meridional shift of the midlatitude westerlies over ACA in spring and summer during the past $21 \mathrm{ka}$ and the associated mechanisms are shown in sections 3 and 4, respectively. We provide some discussion in section 5 and summarize the main conclusions in section 6 .

\section{Data and methods}

\section{a. The TraCE-21ka simulations}

TraCE-21ka are coupled atmosphere-ocean general circulation model simulations performed by the Community Climate System Model version 3 (CCSM3), which are forced by realistic external forcings, including orbital insolation $(\mathrm{ORB})$, greenhouse gases $\left(\mathrm{CO}_{2}\right)$, meltwater fluxes (MWF), and continental ice sheets (ICE) (Fig. 1). In addition to all forcing experiments (TraCE-All), there are four sensitivity experiments driven only by the variation in the ORB (TraCE-ORB), $\mathrm{CO}_{2}$ (TraCE- $\mathrm{CO}_{2}$ ), MWF (TraCEMWF), and ICE (TraCE-ICE) (Liu et al. 2009). All the simulations are conducted with T31_gx3v5 resolution, corresponding to a horizontal resolution of the atmosphere of $3.75^{\circ} \times 3.75^{\circ}$ (Yeager et al. 2006). In the ocean model, the longitudinal resolution is $3.6^{\circ}$, and the latitudinal resolution

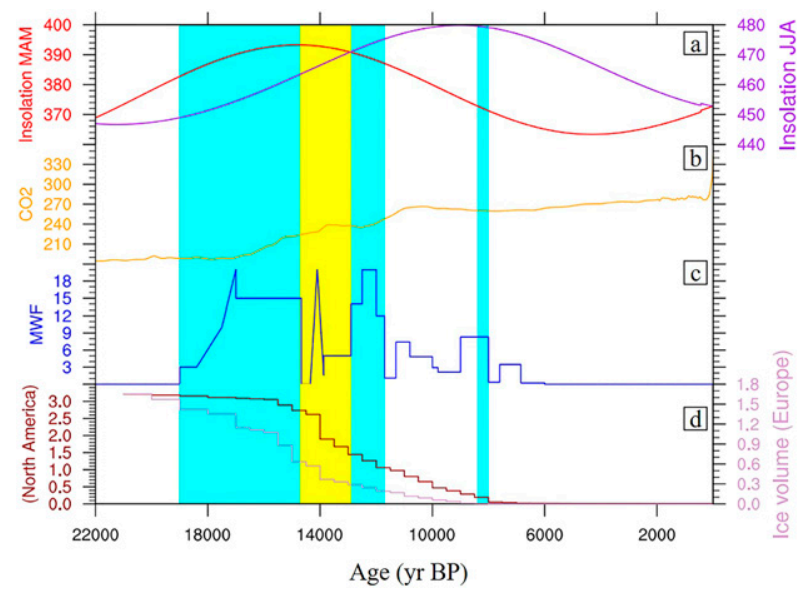

FIG. 1. Evolution of external forcings used in TraCE simulations during the past $22 \mathrm{ka}$. (a) Orbital insolation at $45^{\circ} \mathrm{N}$ in spring (red line) and summer (purple line) (units: $\mathrm{W} \mathrm{m}^{-2}$ ). (b) Atmospheric greenhouse gas concentration (units: ppm). (c) Meltwater fluxes in the Northern Hemisphere (units: meters of global sea level rise per 1000 years). (d) Ice volume of North America (brown line) and Europe (light purple line) (units: $\times 10^{7} \mathrm{~km}^{3}$ ).

is variable, with finer resolution near the equator $\left(\sim 0.9^{\circ}\right)$. More details about the model and experimental design can be found in He (2011). The TraCE-21ka simulations captured the main features of the reconstructed global climate during the past $21 \mathrm{ka}$, such as the Atlantic meridional overturning circulation (Zhu et al. 2014a,b), the East Asian summer and winter monsoons (Wen et al. 2016), and El Niño (Liu et al. 2014).

\section{b. Methods}

In this study, we define the meridional shift of the midlatitude westerlies over ACA as the difference in the mean zonal speed between the domains $40^{\circ}-55^{\circ} \mathrm{N}, 50^{\circ}-$ $80^{\circ} \mathrm{E}$ and $25^{\circ}-40^{\circ} \mathrm{N}, 50^{\circ}-80^{\circ} \mathrm{E}$, which is widely used in previous studies (e.g., Lu 2004; Zhao et al. 2018). The northern branch is defined as zonal winds within the domain $40^{\circ}-55^{\circ} \mathrm{N}, 50^{\circ}-80^{\circ} \mathrm{E}$, and the southern branch is within the domain $25^{\circ}-40^{\circ} \mathrm{N}, 50^{\circ}-80^{\circ} \mathrm{E}$. Although the simulated dipole pattern shows some biases (e.g., locates more southward in summer) compared with observations (discussed in section 2c), the definition of the domains used here has limited influence on our results (see Fig. S1 in the online supplemental material).

We use a simple composite technique to reveal the response of the meridional shift of the midlatitude westerlies over ACA to several external forcings. This is achieved by computing the differences in a certain variable between high and low external periods or before and after a sharp change in external forcings. The composite analysis provides information about both the spatial distribution and the amplitude of the anomaly, 
which is widely used in previous studies (e.g., Ding and Wang 2005; Li et al. 2015; Shi and Yan 2019). In addition, we use Student's $t$ test to assess the statistical significance of the composite results (Wilks 1995).

Over ACA, the meridional shift of the midlatitude westerlies is controlled by the anomalous anticyclone/ cyclone (Zhao et al. 2018). The formation of the anomalous local anticyclone/cyclone can be understood by the investigation of the horizontal propagation of extratropical Rossby waves and the Matsuno-Gill-type response to tropical diabatic heating. An anticyclone/ cyclone with a barotropic structure tends to be induced by the horizontal propagation of extratropical Rossby waves (Ambrizzi et al. 1995). The wave activity flux $(W)$, indicating the horizontal propagation direction of Rossby waves (Takaya and Nakamura 2001), is defined as

$$
W=\frac{1}{2|\bar{U}|}\left[\begin{array}{l}
\bar{u}\left(\psi_{x}^{\prime 2}-\psi^{\prime} \psi_{x x}^{\prime}\right)+\bar{v}\left(\psi_{x}^{\prime} \psi_{y}^{\prime}-\psi^{\prime} \psi_{x y}^{\prime}\right) \\
\bar{u}\left(\psi_{x}^{\prime} \psi_{y}^{\prime}-\psi^{\prime} \psi_{x y}^{\prime}\right)+\bar{v}\left(\psi_{y}^{\prime 2}-\psi^{\prime} \psi_{y y}^{\prime}\right)
\end{array}\right],
$$

where $u$ and $v$ are the zonal and meridional wind velocities, respectively, and $\psi$ is the streamfunction. The overbars and primes denote the climatological states and perturbations, respectively. In this study, we use the long-term mean of the past $21 \mathrm{ka}$ as the climatological state and the anomalies relative to the climatological state during specific periods as the perturbations.

In addition, an anticyclone/cyclone with a baroclinic structure is generally a result of a Matsuno-Gill-type response: forced by tropical diabatic warming (cooling), atmospheric circulation anomalies show an anomalous cyclone (anticyclone) at the lower level and an anomalous anticyclone (cyclone) at the upper level on the northwestern flank of the heating. In the tropics, the anomalous condensational heating induced by anomalous precipitation contributes largely to anomalous diabatic heating. Increased precipitation is accompanied by anomalous convergence in the lower level and divergence in the upper level (Gill 1980; Matsuno 1966). The divergent wind components are calculated as

$$
\begin{aligned}
& \mathbf{V}=\mathbf{V}_{\psi}+\mathbf{V}_{\chi}, \\
& \mathbf{V}_{\chi}=-\nabla \chi,
\end{aligned}
$$

where $\mathbf{V}$ is the velocity vector, $\mathbf{V}_{\psi}$ is the rotational wind, $\mathbf{V}_{\chi}$ is the divergent wind, and $\chi$ is the velocity potential.

Additionally, we use stepwise multiple linear regression (SMLR) to estimate the contribution of different forcings to the meridional shift of the midlatitude westerlies during the last deglaciation (22-11.7 ka) and the Holocene (11.7 ka-1950 AD). The SMLR, which is widely used in previous studies (e.g., Benestad 2005; Christie et al. 2005), is a statistical method of regressing multiple variables, simultaneously removing the weakest correlated variables to obtain the linear relationship that explains the distribution best.

\section{c. Evaluation of the CCSM3 in simulating the current midlatitude westerlies}

The TraCE-All simulation performs well in reproducing the climatological zonal wind at $200 \mathrm{hPa}$ and its leading mode from 1961 to 1990 over ACA $\left(25^{\circ}-55^{\circ} \mathrm{N}\right.$, $50^{\circ}-80^{\circ} \mathrm{E}$ ) (Fig. 2). Specifically, the spatial correlation of 200-hPa zonal winds between the TraCE-All and the reanalysis from the National Centers for Environmental Prediction and National Center for Atmospheric Research (NCEP-NCAR) from 1960 to 1990 is 0.99 both in spring and summer, respectively, although the wind speed is overestimated. Moreover, based on the empirical orthogonal function (EOF) analysis from the NCEP-NCAR reanalysis, the meridional shift (i.e., dipole pattern) is the dominant mode of the zonal wind variations at $200 \mathrm{hPa}$ in spring and summer (Hong et al. 2018; Lu et al. 2011; Yang et al. 2002), which is well captured in the TraCE-All.

\section{Meridional shift of the midlatitude westerlies in spring}

The location of the midlatitude westerlies over ACA in spring exhibits large oscillations during the last deglaciation, whereas it shows a long-term equatorward trend during the Holocene (Fig. 3a). The midlatitude westerlies move equatorward during the Heinrich Stadial 1 (HS1; $17 \mathrm{ka})$ after the LGM ( 21 ka). This is followed by a sudden poleward shift during the Bølling-Allerød (BA; $14.5 \mathrm{ka}$ ) before roughly dropping to the HS1 state during the Younger Dryas (YD; 12.9-11.7 ka). Based on the regression results, such variations are largely attributed to changes in the meltwater fluxes and the continental ice sheets (Figs. 3d-f). Notably, the effect of orbital insolation during the last deglaciation broadly offsets the roles of meltwater fluxes and continental ice sheets (Figs. 3b,d-f). During the early Holocene, the midlatitude westerlies fluctuate near the state of the end of the YD and gradually migrate equatorward during the mid- and late Holocene. This can be attributed to the dominant role of orbital insolation, with limited contributions from the other external forcings (Figs. 3b,f).

Next, we investigate the thermodynamic and dynamic mechanisms responsible for the meridional shift of the midlatitude westerlies in response to individual forcings.

In the MWF experiment, when the meltwater discharge into the North Atlantic weakens during the 

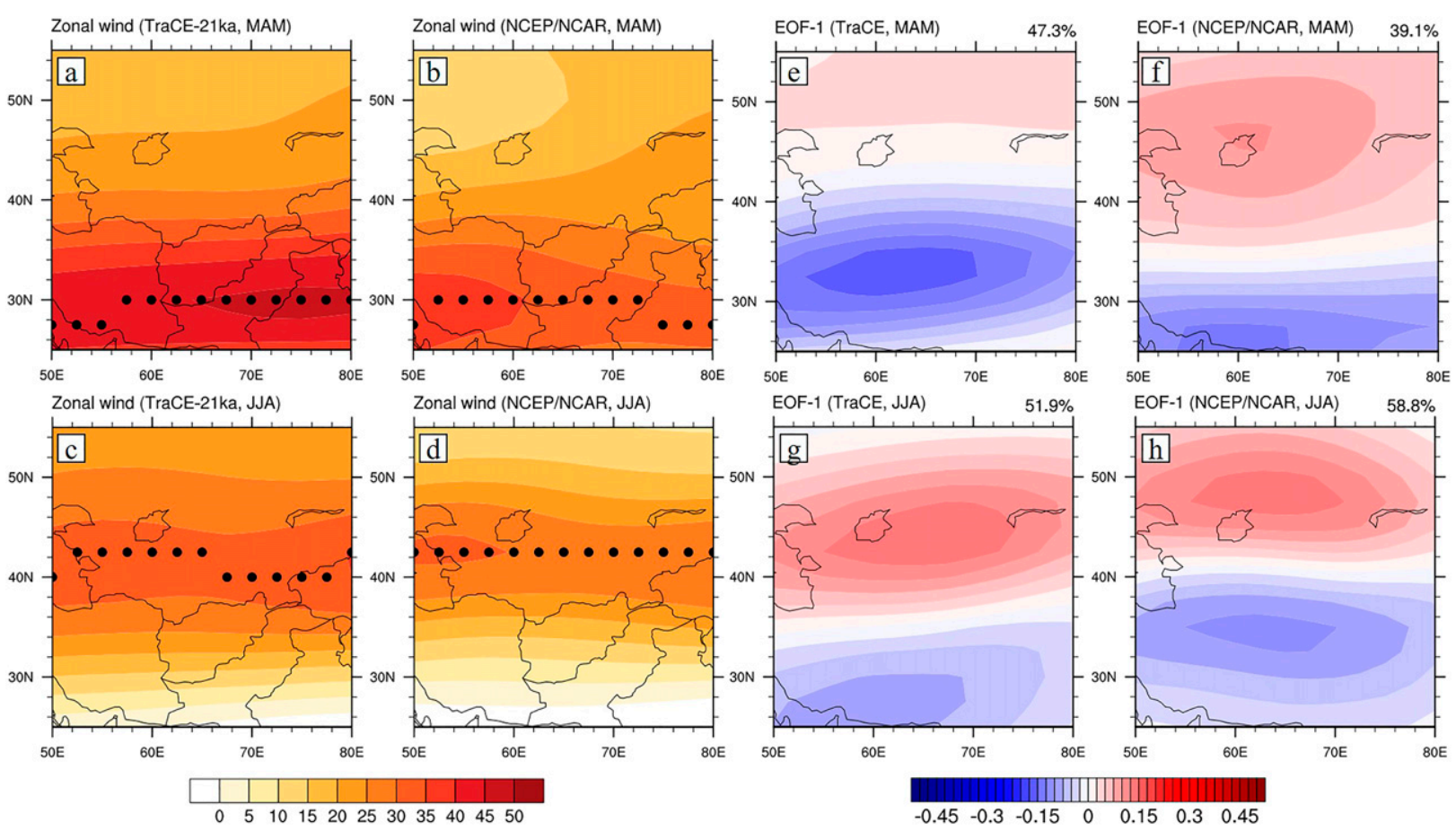

FIG. 2. (a)-(d) Spatial distributions of the climatological zonal wind (units: $\mathrm{m} \mathrm{s}^{-1}$ ) over ACA $\left(25^{\circ}-55^{\circ} \mathrm{N}, 50^{\circ}-80^{\circ} \mathrm{E}\right)$ at $200 \mathrm{hPa}$ in (a), (b) spring and (c),(d) summer from 1961 to 1990. (e)-(h) The leading EOF mode of the zonal wind variations based on the (e),(g) TraCE-21ka simulations and (f),(h) NCEP-NCAR reanalysis in (e),(f) spring and (g),(h) summer. The TraCE-All simulations are regrided to the NCEP-NCAR resolution at $2.5^{\circ} \times 2.5^{\circ}$ by bilinear interpolation. The black dots in (a)-(d) denote the jet axis of the midlatitude westerlies over ACA (i.e., the location of the longitudinal maximum wind speed).

transition from HS1 to BA (Fig. 1), the westerly winds reduce over the entire ACA, with a more profound reduction in the south (Figs. 4a,b). This results in a poleward shift of the midlatitude westerlies. Based on the thermal wind relationship, such variations in zonal winds are linked with the decreased meridional temperature gradient (MTG) at $200-500 \mathrm{hPa}$ in the south (Rojas et al. 2009; Wilcox et al. 2012) (Fig. 4b). Moreover, from the dynamic perspective, variations in zonal wind are attributed to changes in the local atmospheric circulation over ACA. Specifically, the anomalous anticyclone over the Arabian Peninsula and the anomalous cyclone over India are associated with the enhanced and reduced geopotential heights, respectively (Fig. 4c), leading to a remarkable reduction in the westerlies over southern ACA and thereby the poleward migration of the westerlies. Moreover, the formation of the anomalous anticyclone and cyclone over ACA is linked with the horizontal propagation of Rossby waves and tropical diabatic heating anomalies. According to the wave-activity flux, Rossby waves partly originating from western Europe propagate toward the Arabian Peninsula and farther eastward to India (Fig. 4c). However, the anomalous anticyclone over the Arabian Peninsula and the anomalous cyclone over India seem not to be equivalent barotropic, as there are an anomalous cyclone and anticyclone at the lower level over the Arabian Peninsula and India, respectively (Fig. S2c). This indicates an additional role of tropical diabatic heating in the formation of the two anomalous centers. The anomalous cyclone over India is connected to the reduced precipitation over the Bay of Bengal accompanied by anomalous upper-level convergence, which may result from the decrease in local SST (Figs. 4d,e). The reduction in precipitation leads to decreased diabatic heating and hence an anomalous cyclone in its northwest direction at the upper level (i.e., MatsunoGill-type response). In contrast, there is an equatorward shift of the midlatitude westerlies over ACA during the transition from the $\mathrm{BA}$ to the $\mathrm{YD}$, when the meltwater fluxes increase and the Atlantic meridional overturning circulation (AMOC) weakens (Fig. S3).

In the ICE experiment, the anomaly of westerly winds exhibits a dipole pattern during the transition from larger ice sheets to smaller ice sheets (Fig. 1), with reduced zonal wind over south of $40^{\circ} \mathrm{N}$ and intensified wind over the north (Figs. 5a,b). This indicates a poleward migration of the westerlies over ACA in response to the lowering of the midlatitude ice sheets. This 


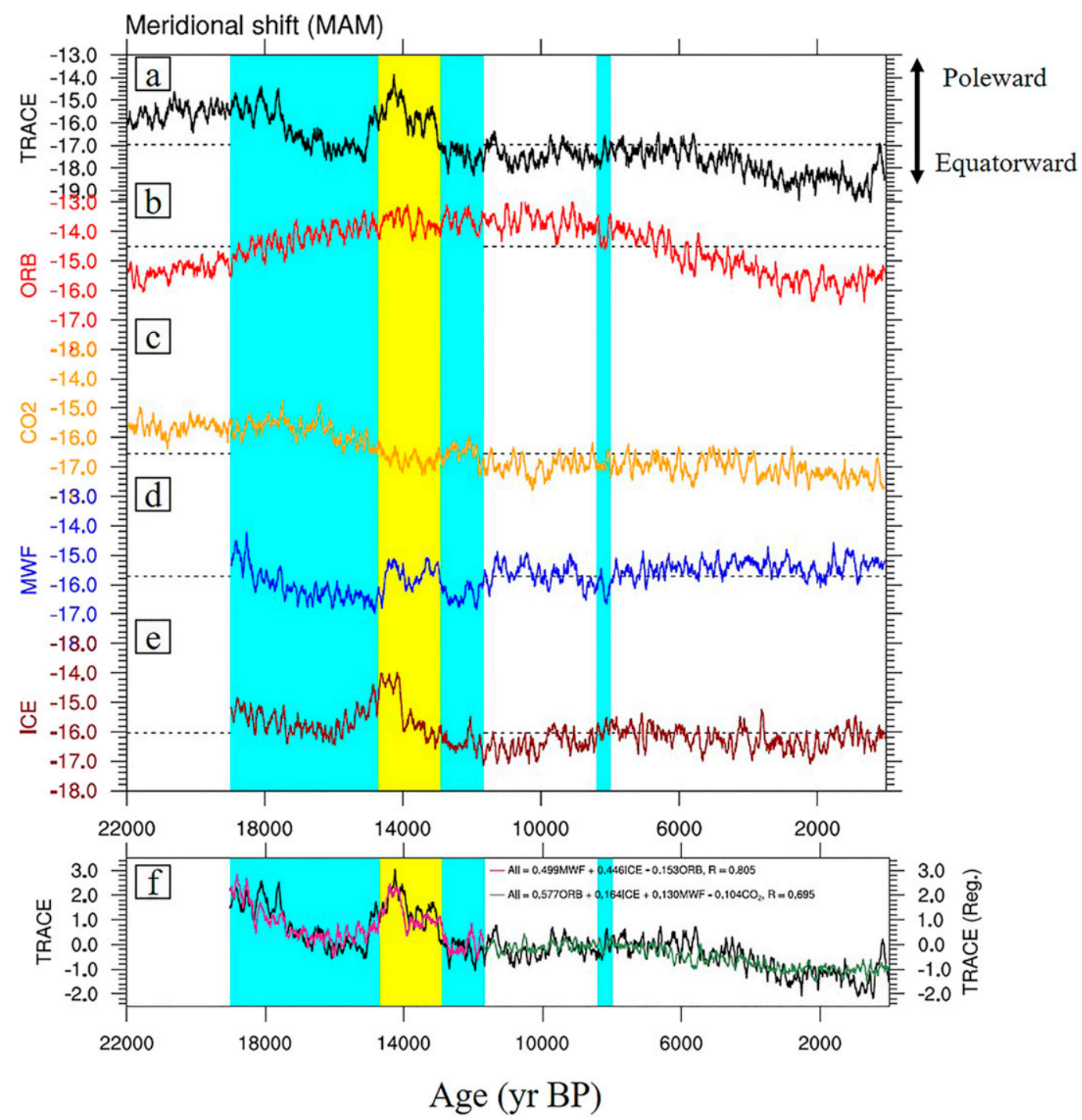

FIG. 3. Evolution of the meridional shift of the spring midlatitude westerlies over ACA during the past 21 ka in the (a) TraCE-All experiment and the experiments forced by varying only (b) orbital insolation (ORB), (c) greenhouse gas concentration $\left(\mathrm{CO}_{2}\right)$, (d) meltwater fluxes (MWF), and (e) continental ice sheets (ICE) by 101yr smoothing. (f) The regressed 101-yr smoothed meridional shift during the last deglaciation (pink line) and the Holocene (green line) based on the four sensitivity experiments compared with the original curve (black line). The three cold events (Heinrich Stadial 1, Younger Dryas, and $8.2 \mathrm{ka}$ ) and the warm event (Bølling-Allerød) are marked as the cyan and yellow vertical panels, respectively. The formulation in (f) is derived from the stepwise multiple linear regression between the meridional shift from the All experiment (dependent variable) and ORB, $\mathrm{CO}_{2}, \mathrm{MWF}$, and ICE experiments (independent variables) during the last deglaciation (pink line) and the Holocene (green line).

matches well with the increased and decreased MTG at 200-850 $\mathrm{hPa}$ over northern and southern ACA, respectively (Fig. 5b). From the dynamic perspective, variations in zonal wind are tied to an anomalous anticyclone (high geopotential height center) over northeastern ACA and the Arabian Peninsula (Fig. 5c). The waveactivity flux indicates that Rossby waves mainly originating from western Europe propagate eastward and branch around the Mediterranean Sea. One branch moves southward to the Arabian Peninsula, favoring the formation of the anomalous anticyclone there. The other branch goes eastward to Siberia. This contributes largely to the establishment of the anomalous anticyclone over northeastern ACA. The circulation anomalies show a baroclinic structure over the Arabian Peninsula with an anomalous cyclone in the lower level (Fig. S2d) and an anomalous anticyclone in the upper level (Fig. 5c). Therefore, the anomalous anticyclone is also related to 
the diabatic heating induced by the increased precipitation over the Indian Ocean resulting from the increased SST, accompanied by the anomalous upper-level divergence (Figs. 5d,e). In contrast, in response to further lowering of ice sheets (high-latitude components of the Laurentide ice sheets), the midlatitude westerlies over ACA migrate equatorward, which is attributed to the fine tuning of the location of anomalous cyclones/anticyclones over ACA (Fig. S4). At a larger scale, the midlatitude westerlies over the Northern Hemisphere still move poleward in response to the lowering of the continental ice sheets.

For the $\mathrm{CO}_{2}$ experiments, the regulation of greenhouse gases on the midlatitude westerlies is relatively weak compared with the meltwater fluxes and continental ice sheets. Therefore, we depict the mechanism briefly. There is an equatorward shift of midlatitude westerlies over ACA arising from the rising $\mathrm{CO}_{2}$, which is attributed to the increased MTG at $200-500 \mathrm{hPa}$ in the south (Fig. 6b). In addition, variations in the westerly winds are associated with the anomalous anticyclone over the Arabian Peninsula and the anomalous cyclone over Xinjiang, which are formed partly by the horizontal propagation of Rossby waves from the dynamic perspective (Fig. 6c). Moreover, the anomalous baroclinic anticyclone over the Arabian Peninsula is also influenced by the Matsuno-Gill-type response to the tropical diabatic heating anomalies, which is induced by increased precipitation over the Arabian Sea accompanied by anomalous upper-level divergence (Fig. 6d). The increased precipitation is caused by the warming of the local SST (Fig. 6e).

For the ORB experiment, the anomaly of westerly winds exhibits a dipole pattern in response to lower insolation from the deglaciation to the mid-Holocene (Fig. 1), with zonal winds intensified south of $35^{\circ} \mathrm{N}$ and slightly weakened over the north, causing an equatorward movement of the midlatitude westerlies over ACA (Figs. 7a,b). The intensified and weakened zonal wind over southern and northern ACA, respectively, is generally tied to the increased MTG in the south at 200$500 \mathrm{hPa}$ (Fig. 7b). This wind pattern is connected with anomalous cyclones (low geopotential height center) over Siberia and the Tibetan Plateau (Figs. 7a,b). The wave-activity flux shown in Fig. 7c suggests that Rossby waves propagate eastward from the North Atlantic to the Mediterranean Sea and then go northeastward to Siberia, indicating the role of the propagation of Rossby waves in maintaining the anomalous cyclone with barotropic structure over Siberia (Fig. 7c, Fig. S2a). Moreover, as deduced from the baroclinic structure of the circulation anomalies over the Tibetan Plateau (Fig. 7c, Fig. S2a), the diabatic cooling induced by reduced precipitation corresponding to the slight SST cooling over the Bay of Bengal and Southeast Asia contributed to the formation of the anomalous cyclone over the Tibetan Plateau (Figs. 7d,e).

In summary, the poleward (equatorward) shift of the midlatitude westerlies in spring over ACA during the BA (YD) is dominated by the reduced (increased) meltwater fluxes and changes in ice sheet topography by modulating the propagation of Rossby waves. The rising $\mathrm{CO}_{2}$ contributes negatively to the poleward (equatorward) shift during the BA (YD), whereas the variation in orbitally induced insolation shows limited influence on the large amplitude shift. In contrast, the decreasing insolation dominates the equatorward migration of the midlatitude westerlies during the Holocene.

\section{Meridional shift of the midlatitude westerlies in summer}

The midlatitude westerlies over ACA are located more equatorward during the LGM, followed by a poleward shift during the last deglaciation, and then migration equatorward during the Holocene (Fig. 8a). In contrast to spring, orbital insolation dominates the overall trend during the past $21 \mathrm{ka}$ in summer (Figs. 8a,b). Based on the regression results, in addition to the orbital insolation forcing, the continental ice sheets also contribute to the poleward shift of the westerlies during the last deglaciation, and the meltwater fluxes and greenhouse gases have a small offsetting and cooperative impact on the equatorward shift during the Holocene, respectively (Figs. 8c-f). In the following paragraphs, we analyze the thermodynamic and dynamic mechanisms of such variations.

In the ORB experiment, when the orbital insolation increases significantly during the early Holocene relative to the LGM (Fig. 1), the anomaly of westerly winds exhibits a dipole pattern, with reduced zonal winds south of the $50^{\circ} \mathrm{N}$ band and intensified winds in the remaining region of ACA (Figs. 9a,b). This indicates a poleward shift of the midlatitude westerlies, which is tied to the decrease in the MTG at 200-500 hPa based on the thermal wind relationship from the thermodynamic perspective (Fig. 9b). Moreover, variations in zonal winds are also associated with the anomalous anticyclone (high geopotential height center) over West Asia from the dynamic perspective. The wave-activity flux shows that Rossby waves originating from western Europe propagate southeastward to ACA (Fig. 9c). This contributes largely to the formation of the anomalous anticyclone over West Asia. However, the circulation anomalies show baroclinic structure over West Asia (Fig. 9c, Fig. S2e). This suggests that the diabatic heating induced by the significantly increased precipitation over 

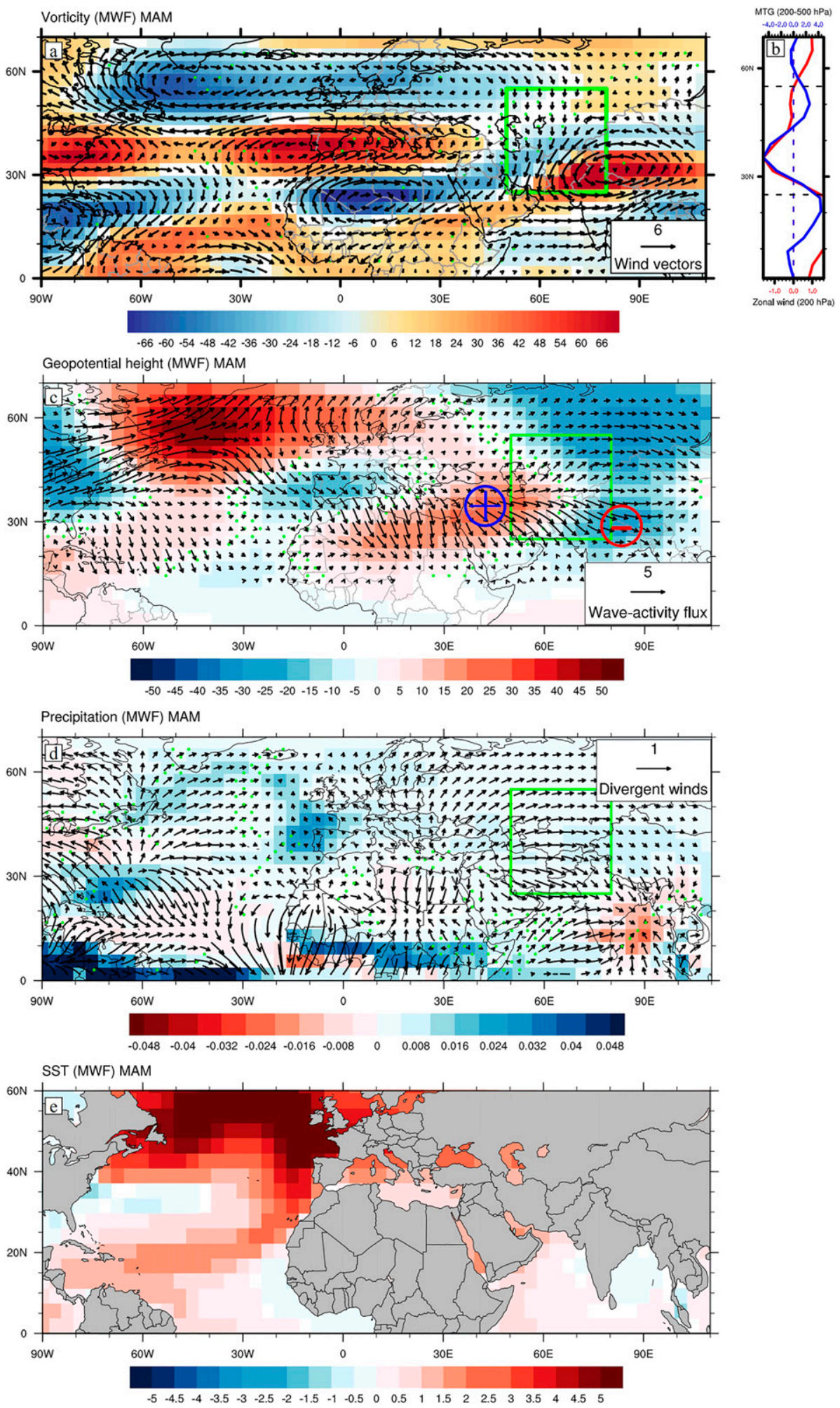

FIG. 4. Anomalies between BA (14.7-13.7 ka) and HS1 (16-15 ka) (BA minus HS1) in the MWF experiment in spring. (a) Relative vorticity (contours; units: $10^{-7} \mathrm{~s}^{-1}$ ) and winds (vectors; units: $\mathrm{m} \mathrm{s}^{-1}$ ) at $200 \mathrm{hPa}$. (b) Zonal winds at $200 \mathrm{hPa}$ (red line; units: $\mathrm{m} \mathrm{s}^{-1}$ ) and meridional temperature gradient [MTG; blue line; units: $\times 10^{2}{ }^{\circ} \mathrm{C}\left({ }^{\circ}\right.$ lat)] at $200-500 \mathrm{hPa}$ averaged between $50^{\circ}$ and $80^{\circ} \mathrm{E}$. (c) Geopotential height with the zonal mean removed (contours; units: gpm) and wave activity flux 
the Sahel and the southern Arabian Peninsula, which is accompanied by anomalous upper-level divergence, also contributes to the anomalous anticyclone over West Asia (Figs. 9c,d). In addition, anomalous diabatic heating over the Tibetan Plateau with an anomalous anticyclone and cyclone in the upper and lower levels suggests that diabatic heating over the Tibetan Plateau may also contribute to changes in midlatitude westerlies over ACA (Fig. S6) (Duan et al. 2008; Hsu and Liu 2003). In contrast, the midlatitude westerlies over ACA move equatorward when orbital insolation decreases during the transition from the late Holocene to the early Holocene (Fig. S7).

For the ICE experiment, the anomaly of westerly winds shows a dipole pattern arising from changes in the larger ice sheets to smaller ice sheets (Fig. 1) with intensified westerly winds appearing north of the $40^{\circ} \mathrm{N}$ band and weakened winds over the remaining part of ACA (Figs. 10a,b). This results in a poleward shift of the midlatitude westerlies over ACA in response to the lowering of the ice sheets. From the thermodynamic perspective, variations in zonal winds are associated with the increased and decreased MTG at $200-850 \mathrm{hPa}$ over northern and southern ACA, respectively (Fig. 10b). Additionally, this wind pattern is connected with the anomalous cyclone (low geopotential height center) over eastern Europe and the anomalous anticyclone (high geopotential height center) over southern ACA from the dynamic perspective (Fig. 10c). As shown by the wave-activity flux, Rossby waves originating from the Mediterranean Sea and Finland converge over eastern Europe and then branch. One branch propagates eastward to Siberia. The other branch moves southeastward to ACA. Therefore, the anomalous cyclone with equivalent barotropic structure over eastern Europe is maintained by the activity of Rossby waves (Fig. 10c, Fig. S2h). Considering that the circulation anomalies over ACA show a baroclinic structure (Fig. 10c, Fig. S2h) in addition to the activity of Rossby waves, the anomalous anticyclone over ACA is also caused by the diabatic heating of the increased precipitation over India corresponding to the anomalous upper-level divergence (Fig. 10d), which is partly attributed to the warming of the SST in the Indian Ocean (Fig. 10e).

Compared with orbital insolation and continental ice sheets, the impacts of greenhouse gases and meltwater fluxes on the midlatitude westerlies are relatively weaker. The brief dynamic mechanism is described as follows. In the $\mathrm{CO}_{2}$ experiment, the rising $\mathrm{CO}_{2}$ leads to a poleward shift of the midlatitude westerlies over ACA (Figs. 11a,b). Such wind variations share similarity with the MTG at 200-500 hPa over ACA based on the thermal wind relationship (Fig. 11b). Moreover, the wind patterns are also regulated by the anomalous cyclone over northeastern ACA and the anomalous anticyclone over southwestern ACA extending from the Arabian Peninsula, which are the results of Rossby wave propagation (Fig. 11c). In addition, the circulation anomalies show a baroclinic structure over the Arabian Peninsula to southwestern ACA (Fig. 11c, Fig. S2f). Therefore, diabatic heating induced by increased precipitation due to the SST warming over the Indian Ocean is also involved in maintaining this anomalous center (Figs. 11d,e). Besides, diabatic heating over the Tibetan Plateau may also contribute to variations in the midlatitude westerlies over ACA, for anomalous diabatic heating over the Tibetan Plateau is accompanied with anomalous baroclinic structure (Fig. S6) (Duan et al. 2008; Hsu and Liu 2003).

In response to a weaker meltwater discharge during BA relative to HS1 (Fig. 1), the midlatitude westerlies over ACA move poleward (Figs. 12a,b). Zonal wind variations can be attributed to changes in the MTG at 200-850 hPa over ACA based on the thermal wind relationship from the thermodynamic perspective (Fig. 12b). In addition, these variations are dominated by the anomalous cyclone over West China and the anomalous anticyclone over the Arabian Peninsula from the dynamic perspective, linked with the horizontal propagation of Rossby waves (Fig. 12c). Moreover, the circulation anomalies exhibit a baroclinic structure over the Arabian Peninsula and West China (Fig. 12c, Fig. S2g). Therefore, the diabatic heating induced by increased precipitation owing to the SST warming in the Indian Ocean contributes substantially to the anomalous anticyclone over the Arabian Peninsula (Figs. 12d,e). In contrast, there is an equatorward shift of the midlatitude westerlies over ACA during the transition from the $\mathrm{BA}$ to the $\mathrm{YD}$, when the meltwater fluxes increase again and thereby the AMOC weakens. (Fig. S8).

In summer, the poleward migration of the midlatitude westerlies over ACA during the last deglaciation (19$11.7 \mathrm{ka})$ is controlled by increased insolation and decreased

(vectors; units: $\mathrm{m}^{2} \mathrm{~s}^{-2}$ ) at $200 \mathrm{hPa}$. (d) Precipitation (contours; units: $\mathrm{mm}$ month ${ }^{-1}$ ) and divergent winds (vectors; units: $\mathrm{m} \mathrm{s}^{-1}$ ) at $200 \mathrm{hPa}$. (e) Sea surface temperature (SST) (units: ${ }^{\circ} \mathrm{C}$ ). The green box in (a), (c), and (d) indicates the ACA region. The positive (negative) sign in the circle in (b) denotes the anomalous anticyclone (cyclone) regulating the wind patterns over ACA. Areas not passing the $95 \%$ significance test are masked for contours and dotted for vectors. 

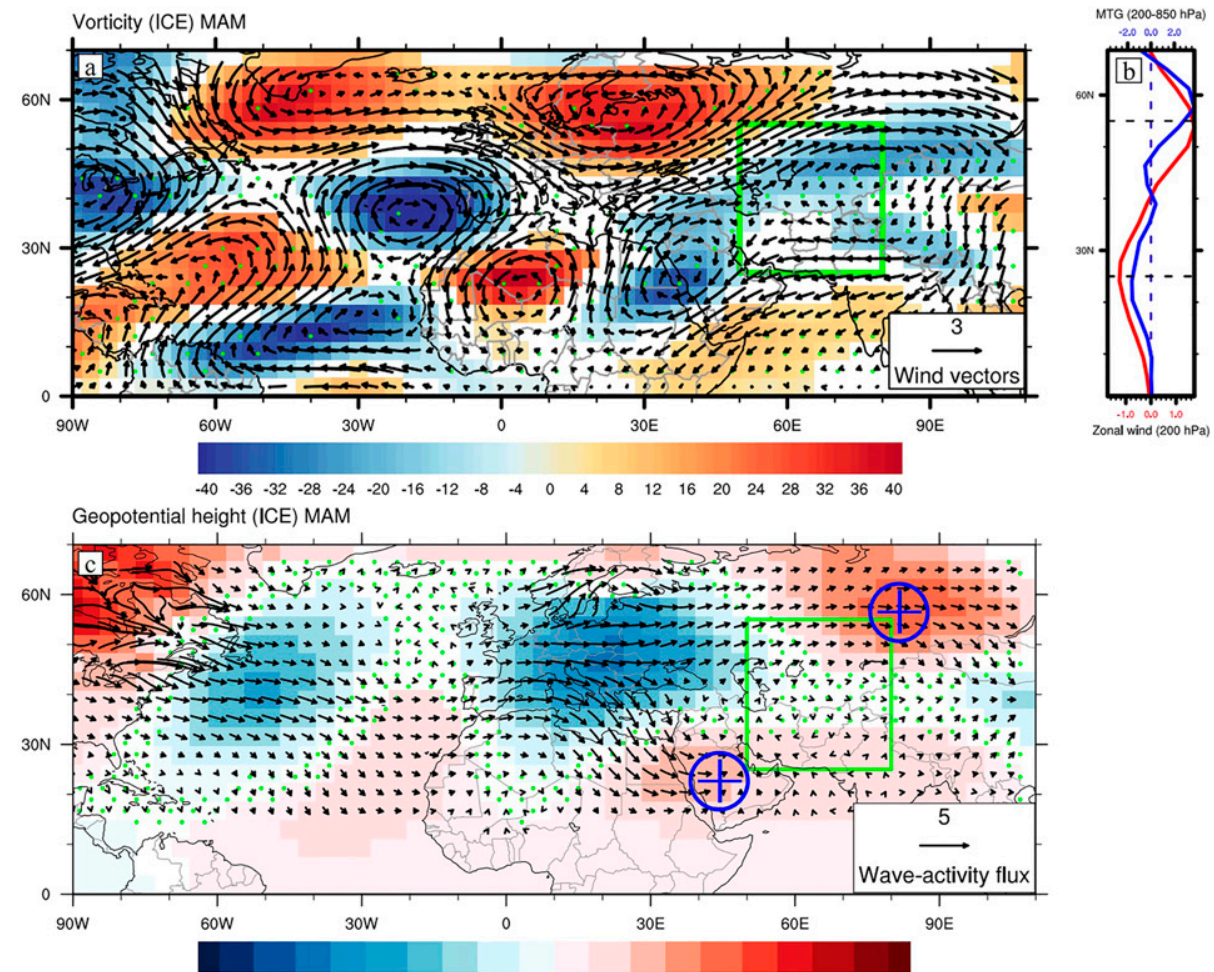

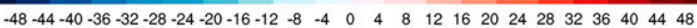

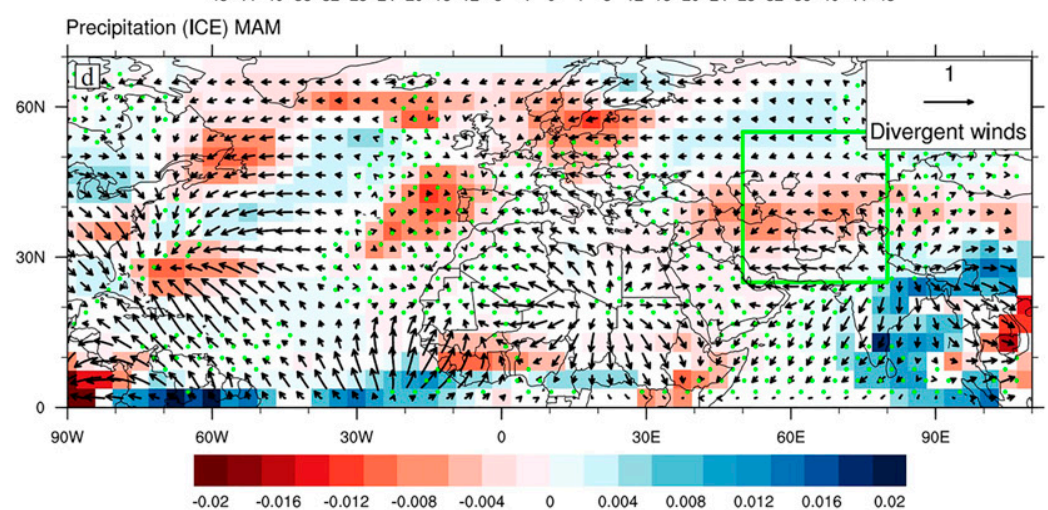

SST (ICE) MAM

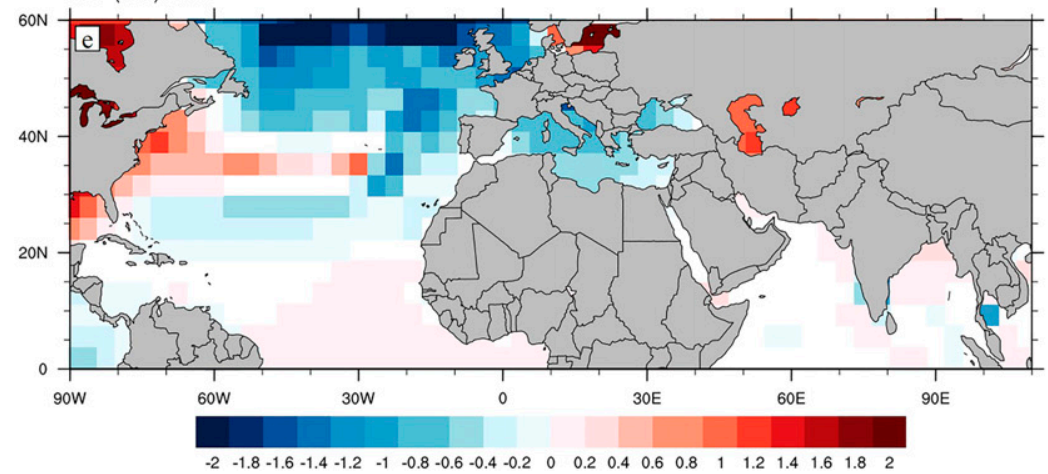

FIG. 5. As in Fig. 4, but for anomalies between the smaller ice sheets (14.7-14.2 ka) and the larger ice sheets (16.5-16.0 ka) (the smaller ice sheets minus the larger ice sheets) in the ICE experiment in spring. 

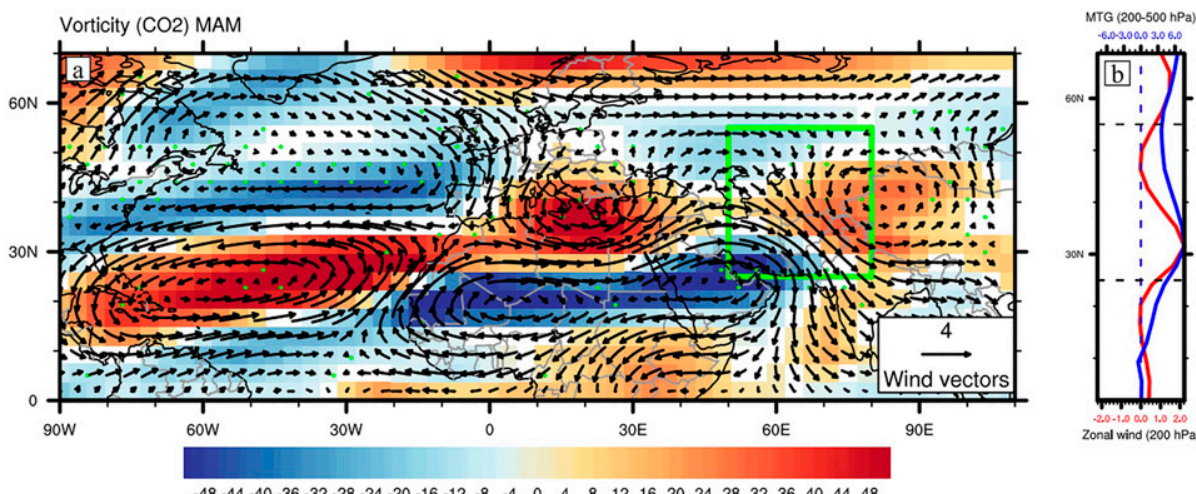

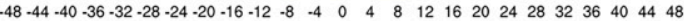

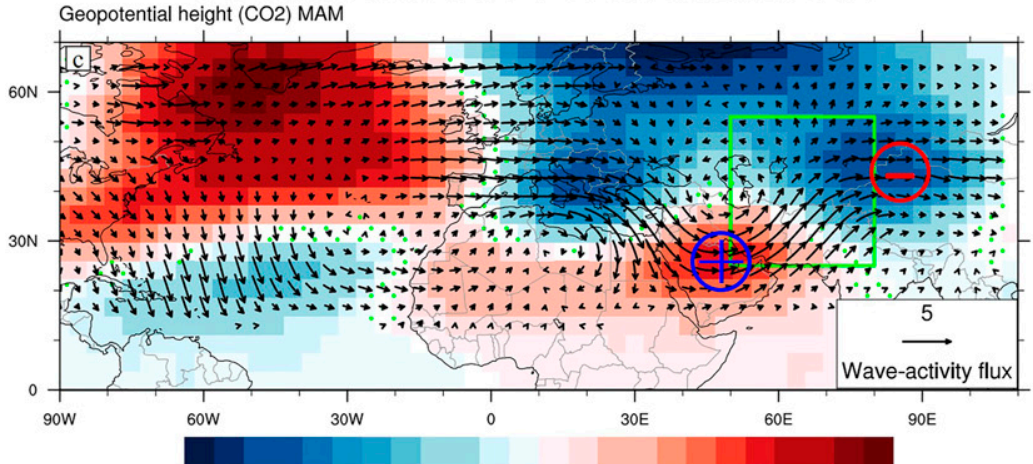

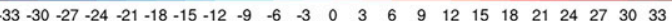

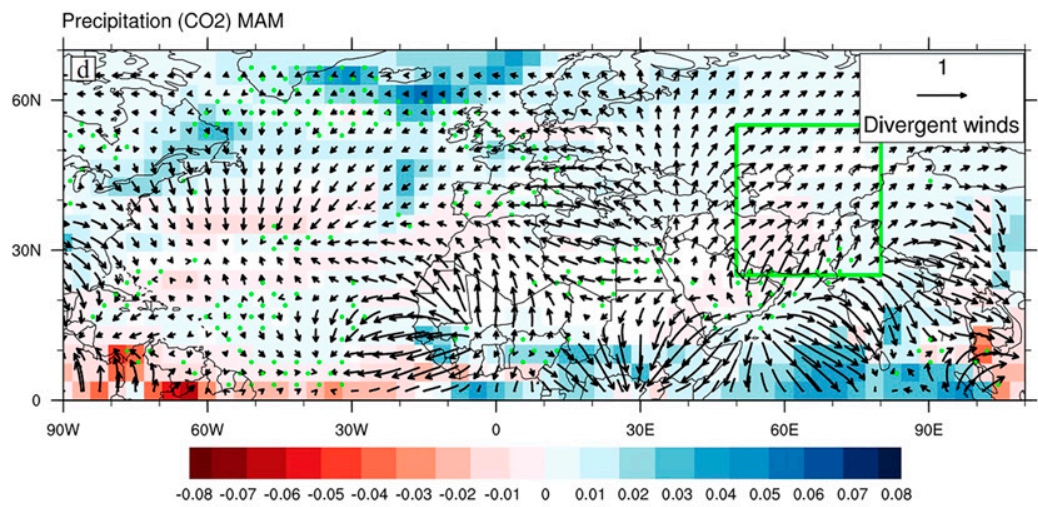

SST (CO2) MAM

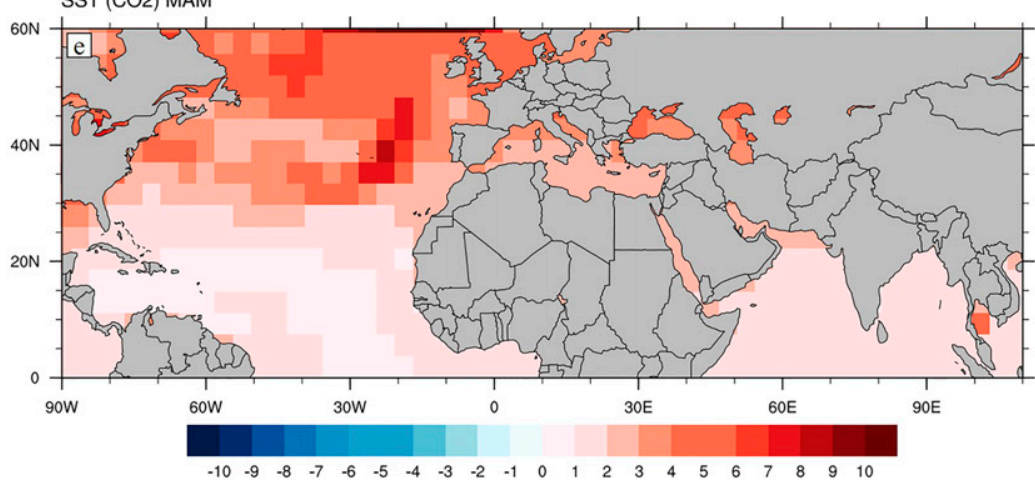

FIG. 6. As in Fig. 4, but for anomalies between high-greenhouse gas periods (11-10 ka) and lowgreenhouse gas periods (22-21 ka) (high-minus low-greenhouse gas periods) in the $\mathrm{CO}_{2}$ experiment in spring. 

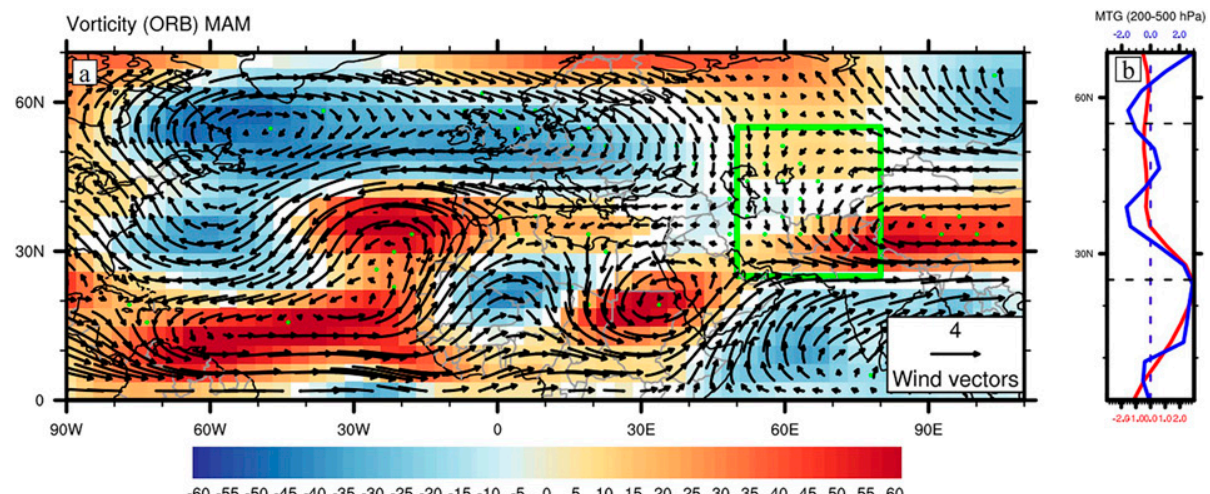

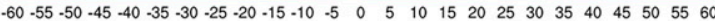

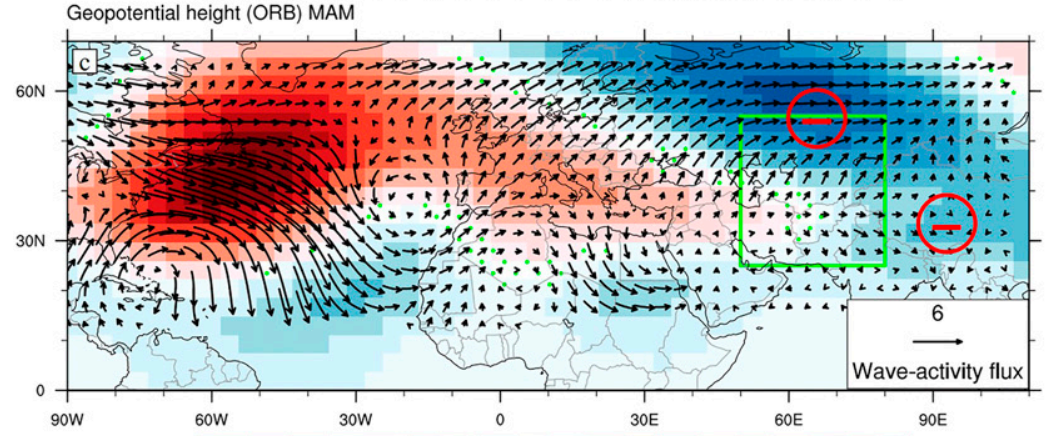

$-60-55-50-45-40-35-30-25-20-15-10-5 \quad 0 \quad 5 \quad 10 \quad 15 \quad 20 \begin{array}{llllllll}25 & 30 & 35 & 40 & 45 & 50 & 55 & 60\end{array}$

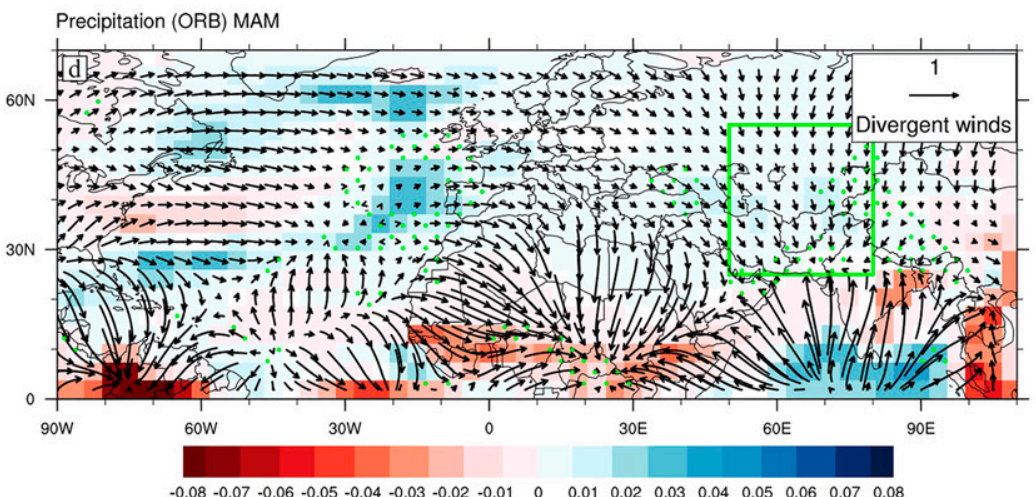

SST (ORB) MAM

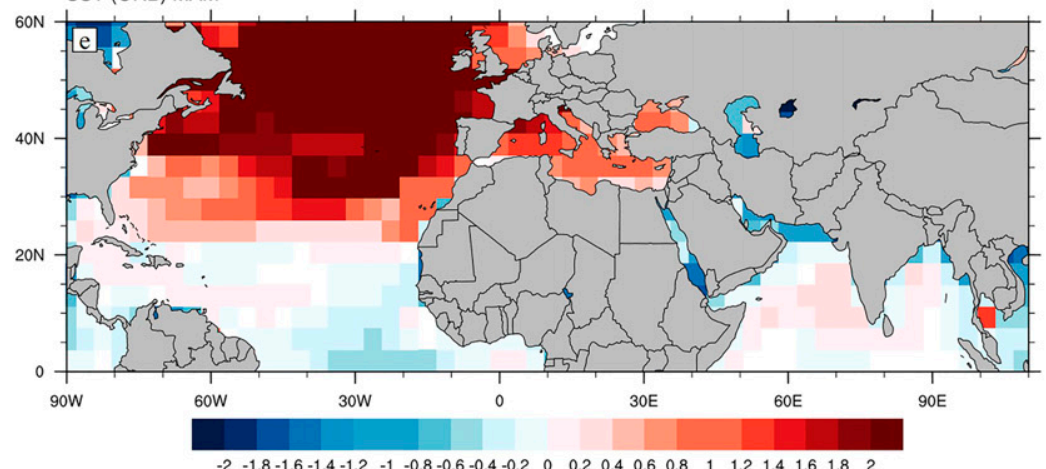

FIG. 7. As in Fig. 4, but for anomalies between the mid-Holocene (5.0-4.0 ka) and the deglaciation $(15.5-14.5 \mathrm{ka})$ (the mid-Holocene minus the deglaciation) in the ORB experiment in spring. 


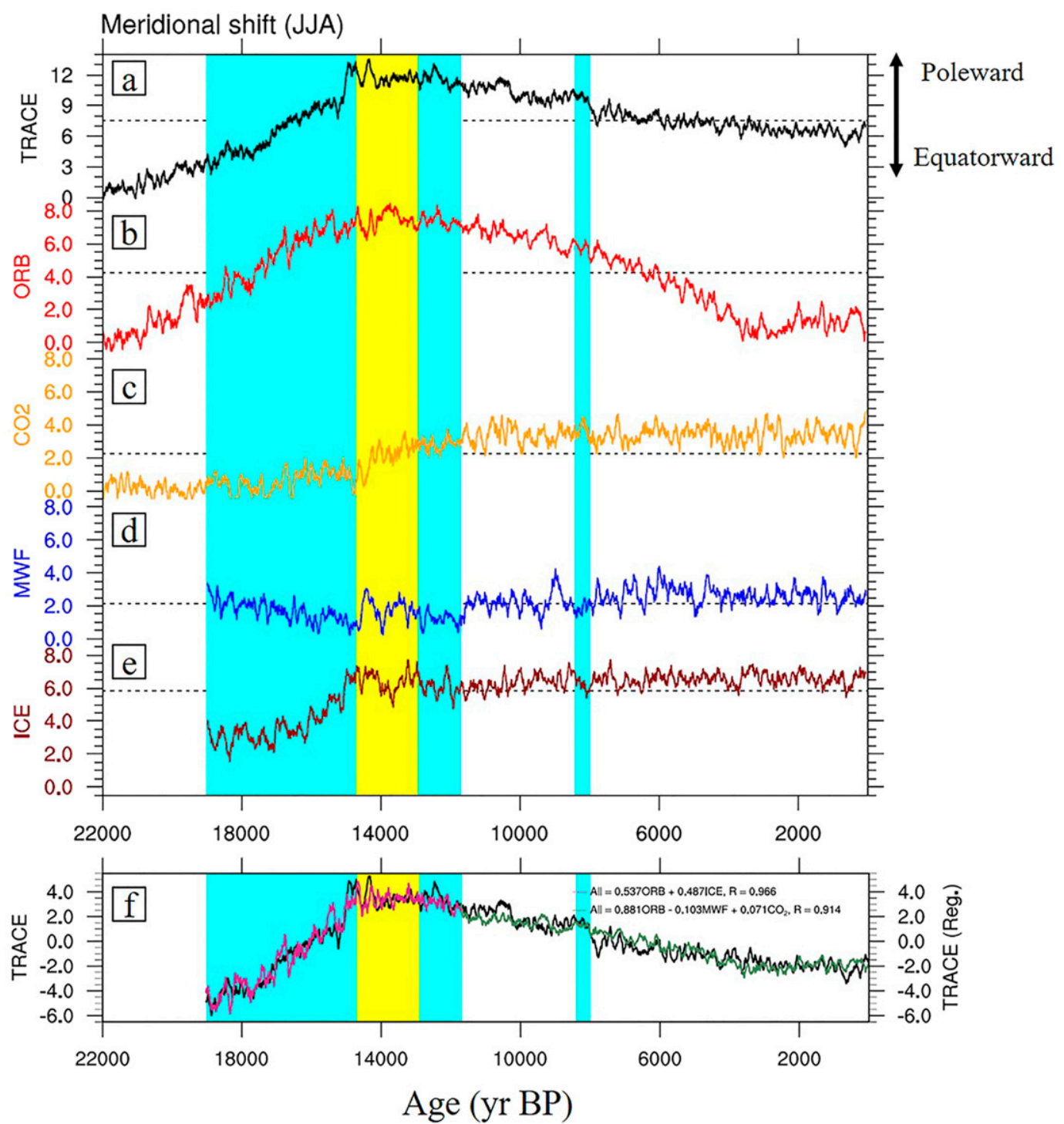

FIG. 8. As in Fig. 3, but for the evolution of midlatitude westerlies over ACA in summer.

continental ice sheet topography through changing tropical diabatic heating and triggering Rossby wave propagation. The rising $\mathrm{CO}_{2}$ contributes positively to the poleward migration, whereas the meltwater fluxes play a contrary role. During the Holocene, the equatorward movement is generally controlled by reduced insolation, with limited contributions from other forcings (note that change in $\mathrm{CO}_{2}$ influences the meridional shift on centennial scale, but its impact is very small at longer time scale).

\section{Discussion}

\section{a. Comparisons between spring and summer}

In this subsection, we discuss the similarities and differences in the meridional shift of the midlatitude westerlies over ACA between spring and summer. Although the external forcings used have no seasonal variations except for orbital insolation, the magnitude of the temperature response to external forcings varies by season, as seen in the present day. The combined effect of individual forcings on the westerlies is hence dependent on the seasons we analyzed, as the meridional temperature gradient shapes the zonal winds substantially (Rojas et al. 2009; Wilcox et al. 2012). During the LGM, the midlatitude westerlies over ACA exhibit a poleward migration in spring, whereas they are located more equatorward in summer. The external forcings exhibit no significant variation during the LGM except for orbital insolation. However, the poleward shifts induced by the increased insolation are similar in spring 

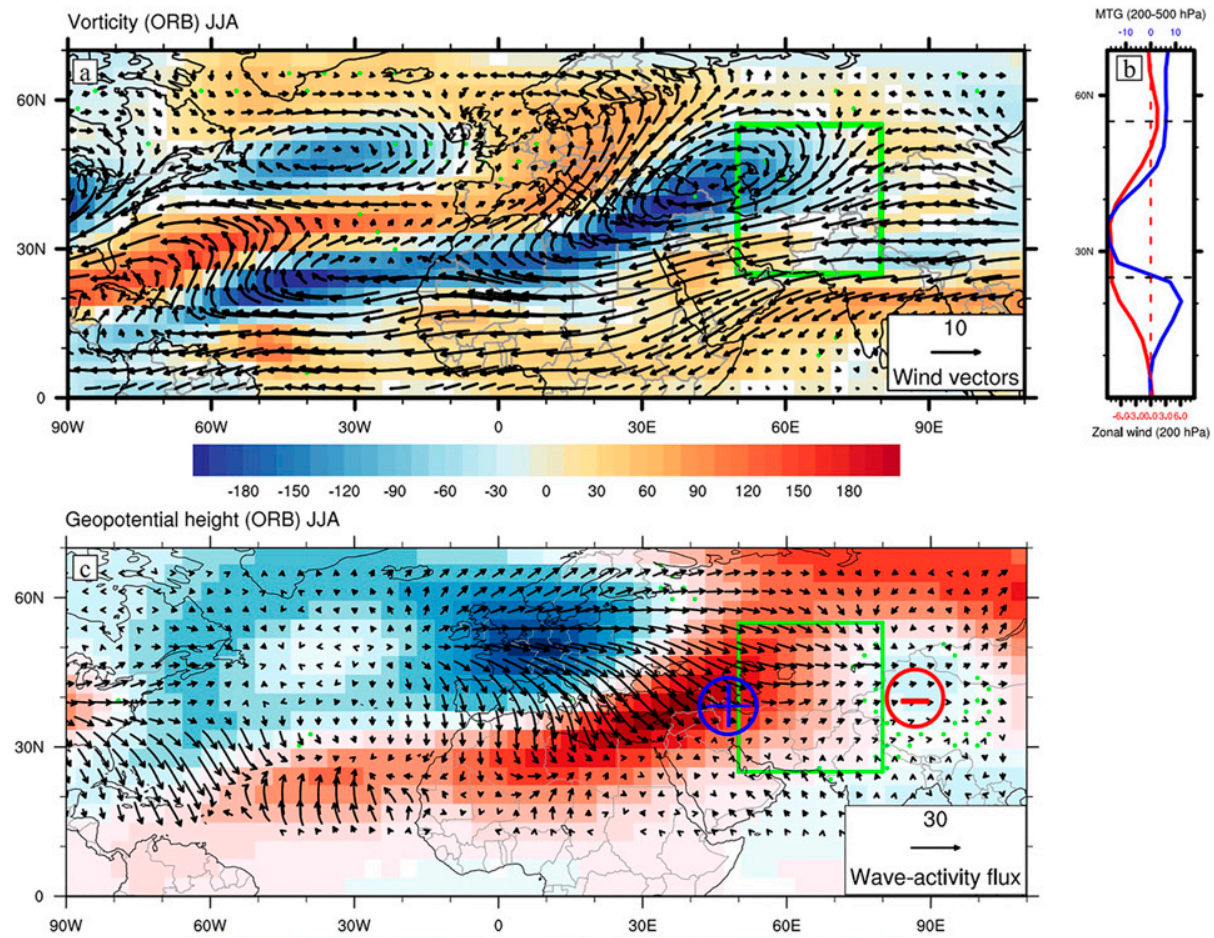

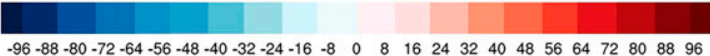

Precipitation (ORB) JJA

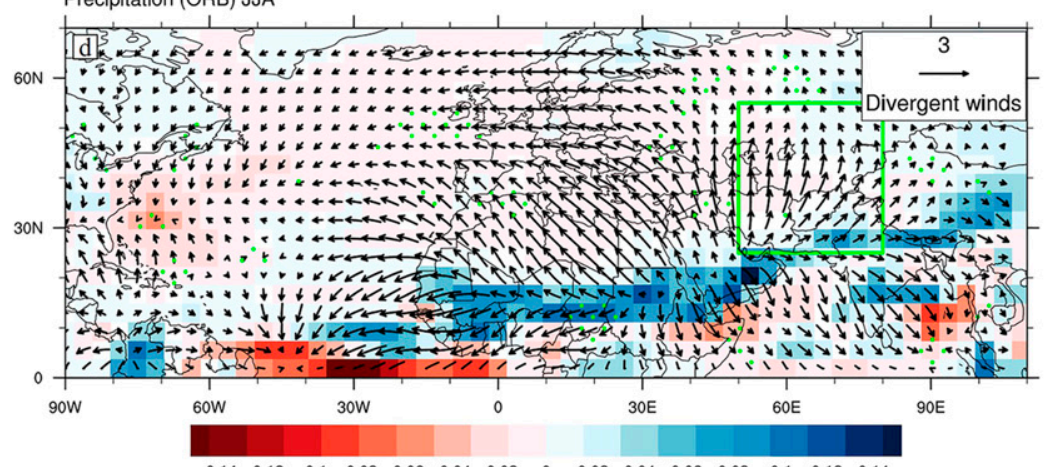

SST (ORB) JJA

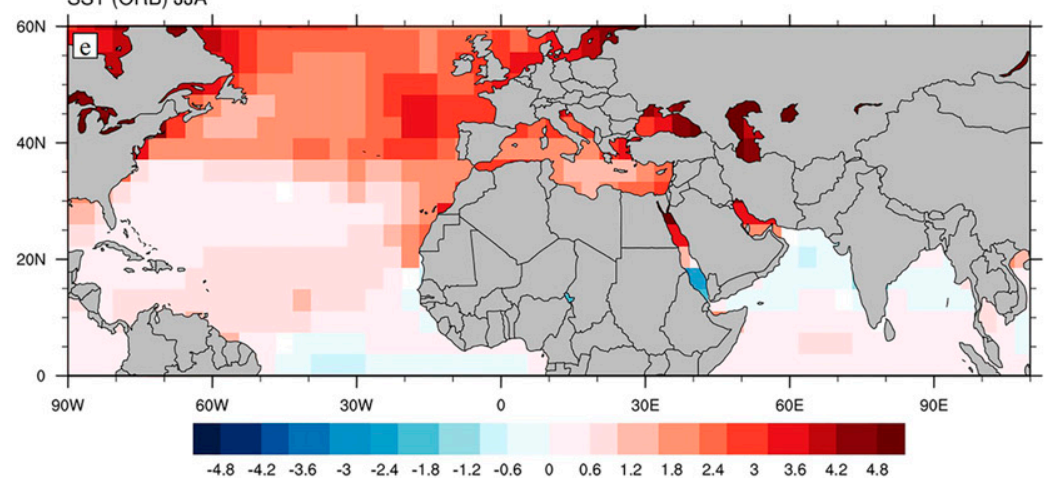

FIG. 9. As in Fig. 4, but for anomalies between the early Holocene (11.0-10.0 ka) and the LGM (22.0$21.0 \mathrm{ka}$ ) (the early Holocene minus the LGM) in the ORB experiment in summer. 

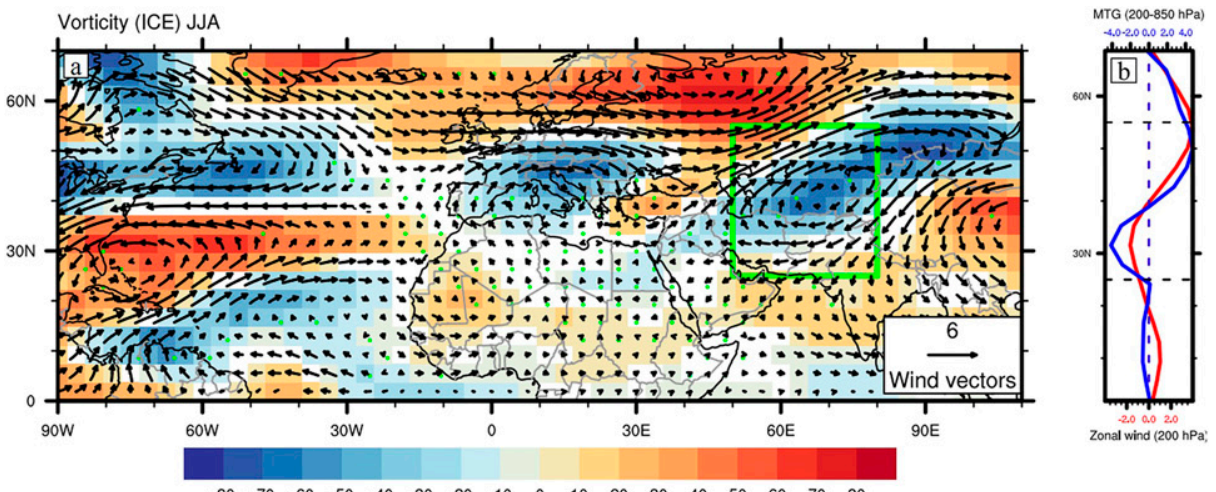

$\begin{array}{rrrrrrrrrrrrrrrrr}-80 & -70 & -60 & -50 & -40 & -30 & -20 & -10 & 0 & 10 & 20 & 30 & 40 & 50 & 60 & 70 & 80\end{array}$

Geopotential height (ICE) JJA

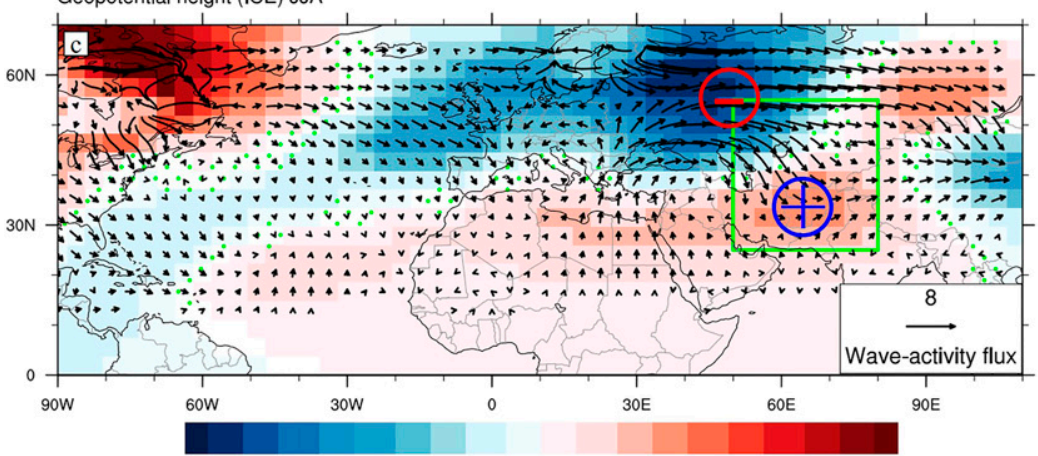

$-60-55-50-45-40-35-30-25-20-15-10-5 \quad 0 \quad 5 \quad 10 \quad 15 \quad 20 \begin{array}{llllllll}25 & 30 & 35 & 40 & 45 & 50 & 55 & 60\end{array}$ Precipitation (ICE) JJA

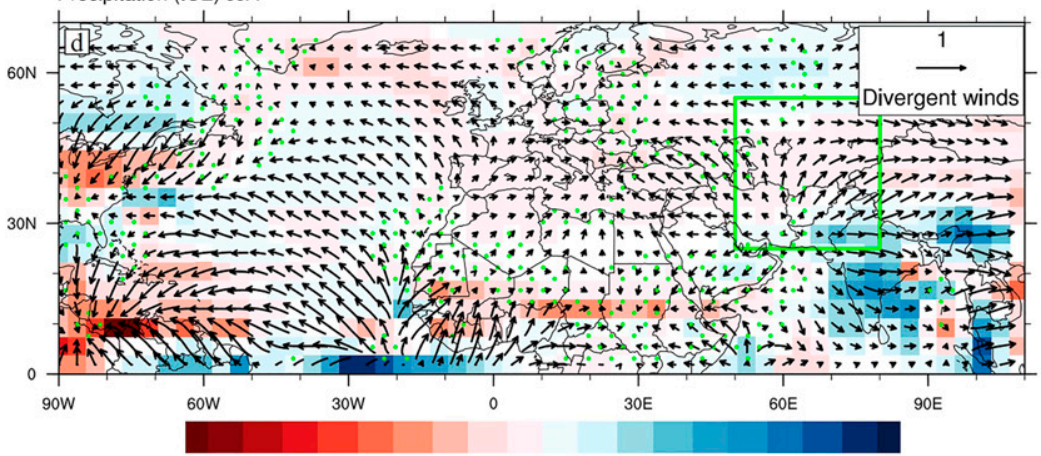

SST (ICE) JJA

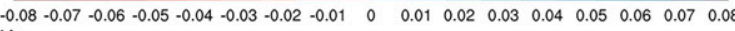

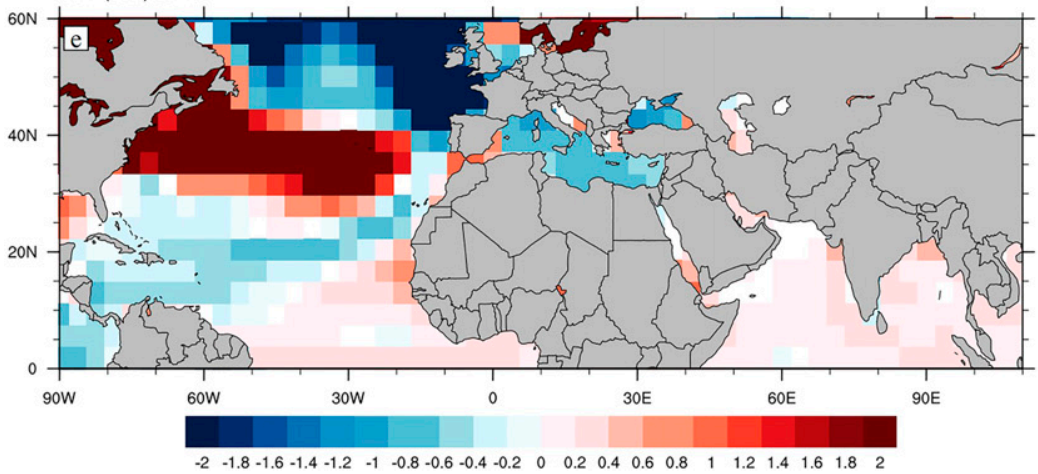

FIG. 10. As in Fig. 4, but for anomalies between the smaller ice sheets (13.5-13.0 ka) and the larger ice sheets (17.5-17.0 ka) (the smaller ice sheets minus the larger ice sheets) in the ICE experiment in summer. 

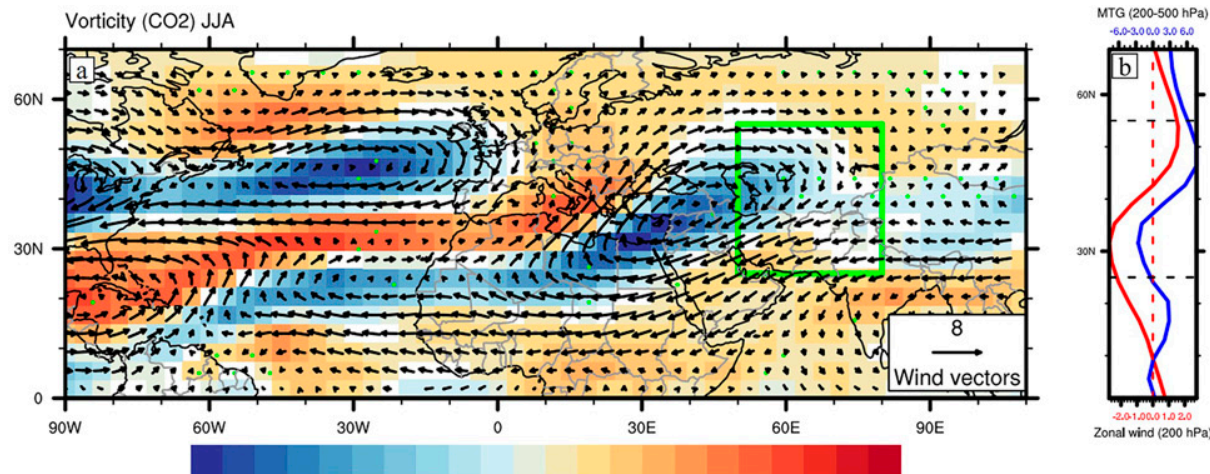

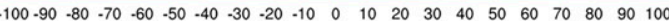

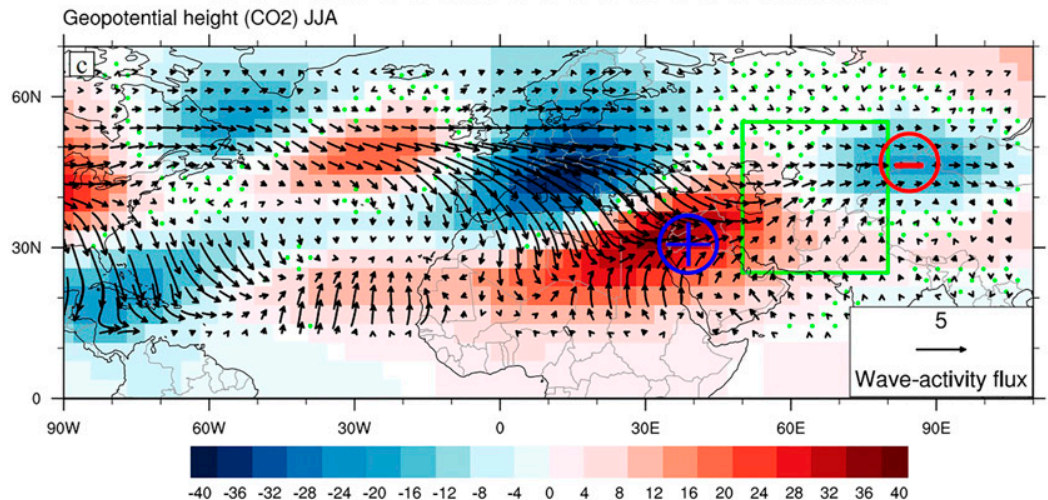

Precipitation (CO2) JJA

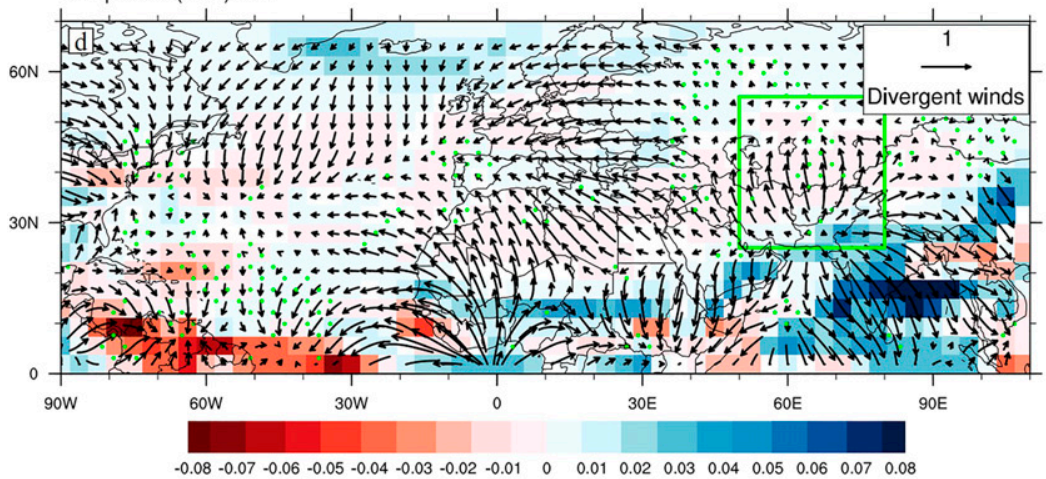

SST (CO2) JJA

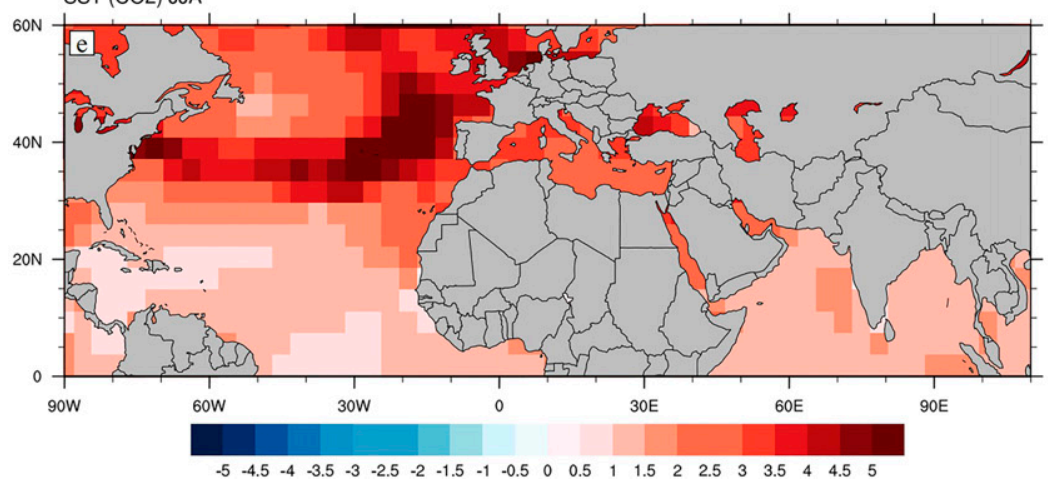

FIG. 11. As in Fig. 4, but for anomalies between high-greenhouse gas periods (11-10 ka) and lowgreenhouse gas periods (22-21 ka) (high- minus low-greenhouse gas periods) in the $\mathrm{CO}_{2}$ experiment in summer. 

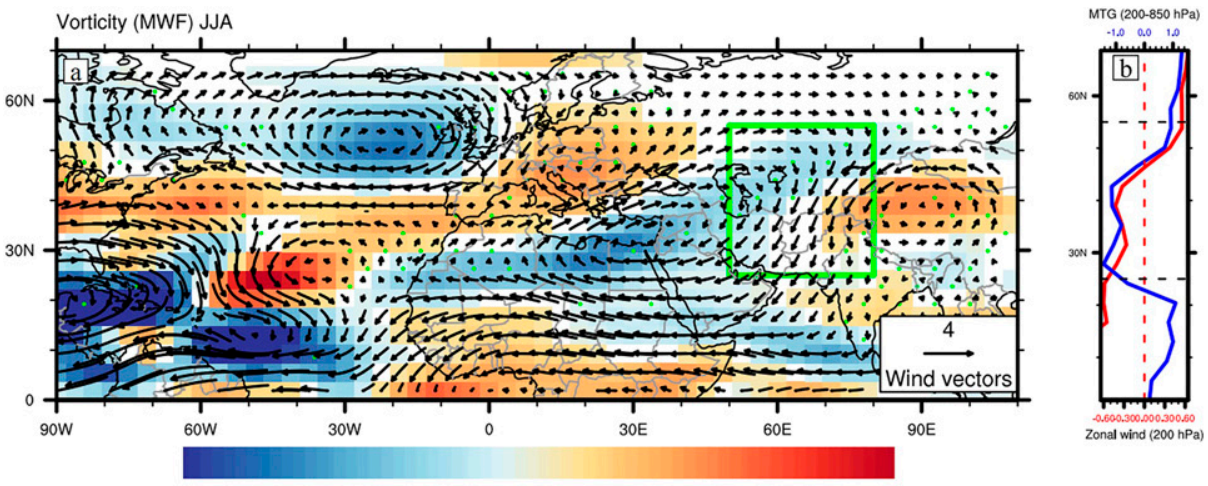

Geopotential height (MWF) JJA

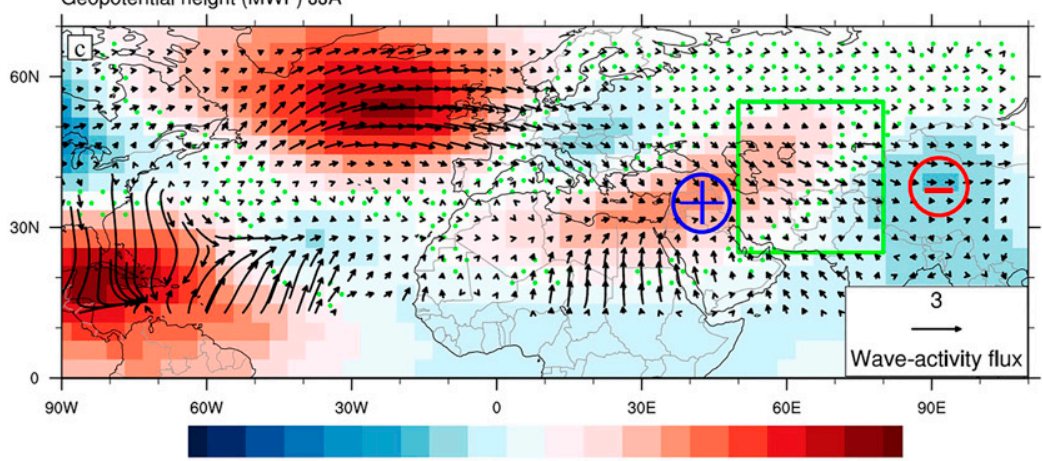

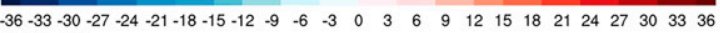
Precipitation (MWF) JJA

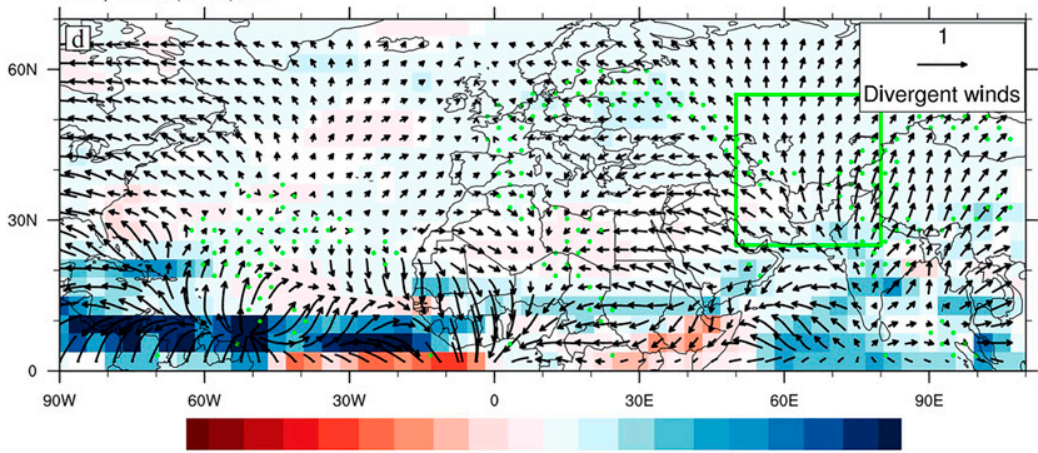

SST (MWF) ${ }^{-0.08} \mathrm{JA}$

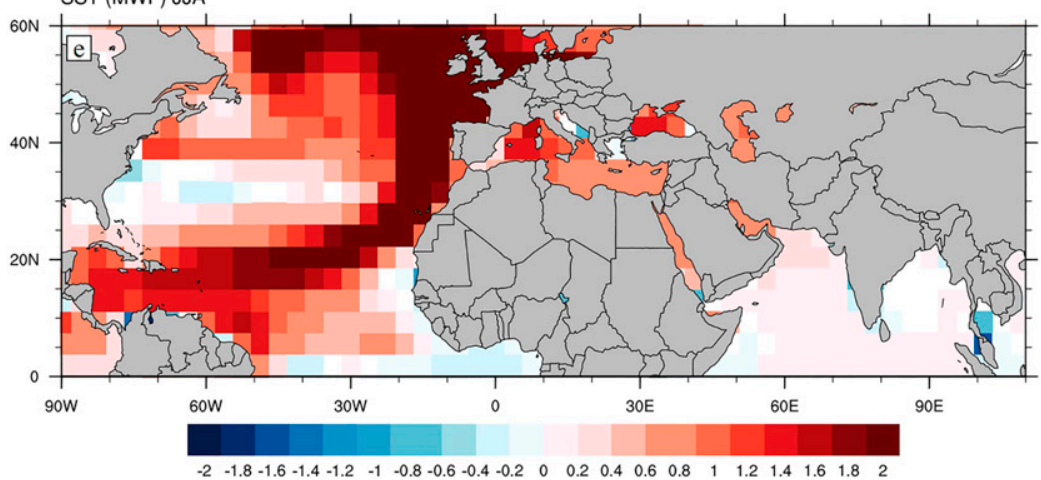

FIG. 12. As in Fig. 4, but for anomalies between BA (14.7-13.7 ka) and HS1 (16-15 ka) (BA minus HS1) in the MWF experiment in summer. 


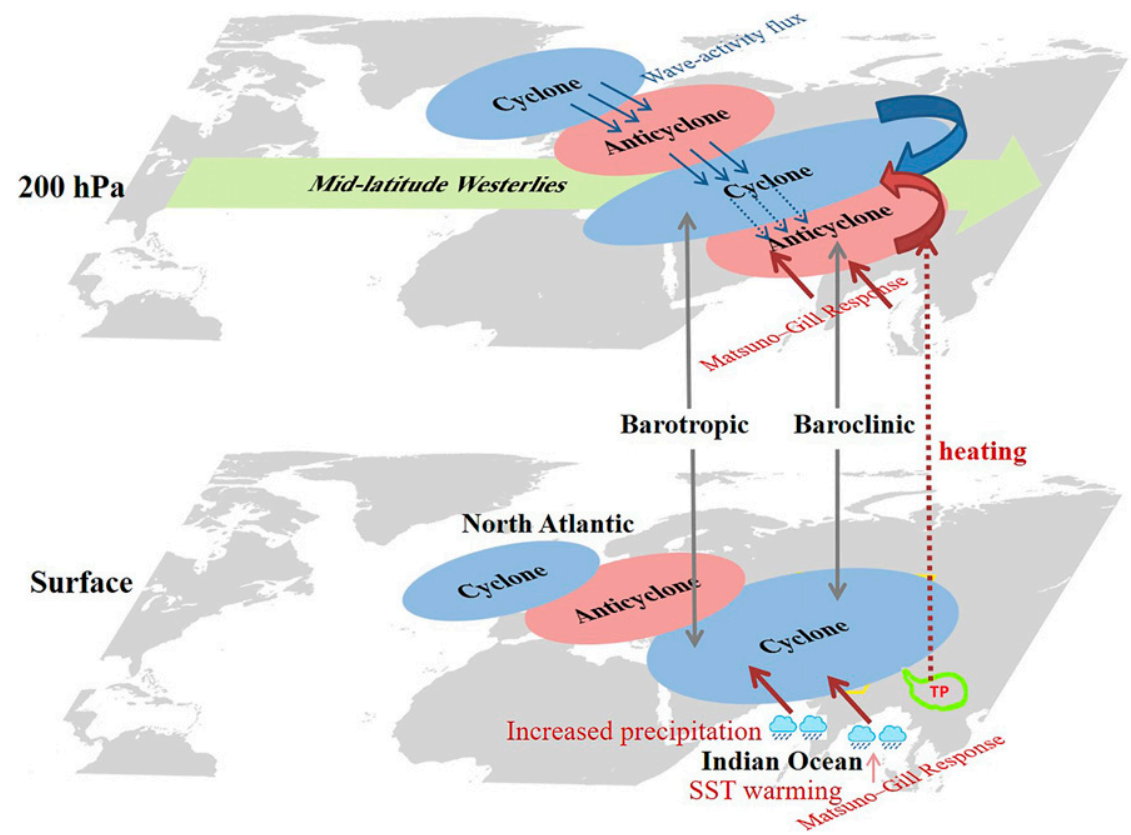

FIG. 13. Schematic diagram for the midlatitude westerlies over ACA regulated by anomalous circulations (i.e., cyclones and anticyclones) induced by the propagation of Rossby waves and the Matsuno-Gill response. The green stripe represents the midlatitude westerlies in the upper troposphere $(200 \mathrm{hPa})$. Anomalous circulations with barotropic structures (e.g., anomalous cyclones at $200 \mathrm{hPa}$ are accompanied by cyclonic anomalies at the surface) largely result from the propagation of Rossby waves from upstream, as indicated by the wave activity flux (solid blue vectors). In contrast, anomalous circulations with baroclinic structures (e.g., anomalous anticyclones at $200 \mathrm{hPa}$ are accompanied by cyclonic anomalies at the surface) are mainly caused by the Matsuno-Gill response induced by anomalous precipitation arising from changes in SSTs, with contributions from the propagation of Rossby waves (dashed blue vectors). Heating over the Tibetan Plateau (TP) may also contribute to anomalous circulations with baroclinic structures at $200 \mathrm{hPa}$. This holds for the opposite conditions of the schematic diagram.

and summer. Therefore, the differences between the meridional shift in spring and summer may be attributed to diverse responses of temperature across seasons and the nonlinear interactions among various forcings. Moreover, in spring, the midlatitude westerlies migrate equatorward, poleward, and equatorward during HS1, $\mathrm{BA}$, and YD, respectively, and show consistent poleward migration in summer. According to the multiple linear regression results, the meltwater fluxes and continental ice sheets are dominant contributors in regulating the spring midlatitude westerlies during these periods, and orbital insolation contributes greatly in summer. This is because the orbital insolation in summer varies more intensely than in spring and thereby induces more remarkable variations in the midlatitude westerlies, which exceeds the influences of the other factors. In addition, both the spring and summer midlatitude westerlies over ACA have an equatorward trend during the Holocene, with orbital insolation being the dominant contributor. Overall, these results indicate that the dominant driving factors vary with season and time over ACA.

Notably, the variation in the midlatitude westerlies does not closely match the evolution of seasonal mean insolation. For example, spring insolation increases significantly during the last $2 \mathrm{ka}$, but there is only a slight poleward shift of the spring midlatitude westerlies in the ORB experiment. In summer, the stable fluctuation near the state of 2 ka seems inconsistent with decreasing insolation. Compared with the monthly insolation (Fig. S9), spring insolation is most similar to that in April, while the meridional shift of the westerlies over the last $2 \mathrm{ka}$ is largely similar to the insolation in May. Similarly, the insolation in July is the major contributor to the summer insolation, while for the meridional shift of the midlatitude westerlies during the past $2 \mathrm{ka}$, the insolation in June plays a more important role. Our results are similar to the findings of Shi and Yan (2019) that highlighted a lagged response of Asian monsoons to orbital insolation. Given the lack of monthly outputs from the ORB sensitivity experiment, the 


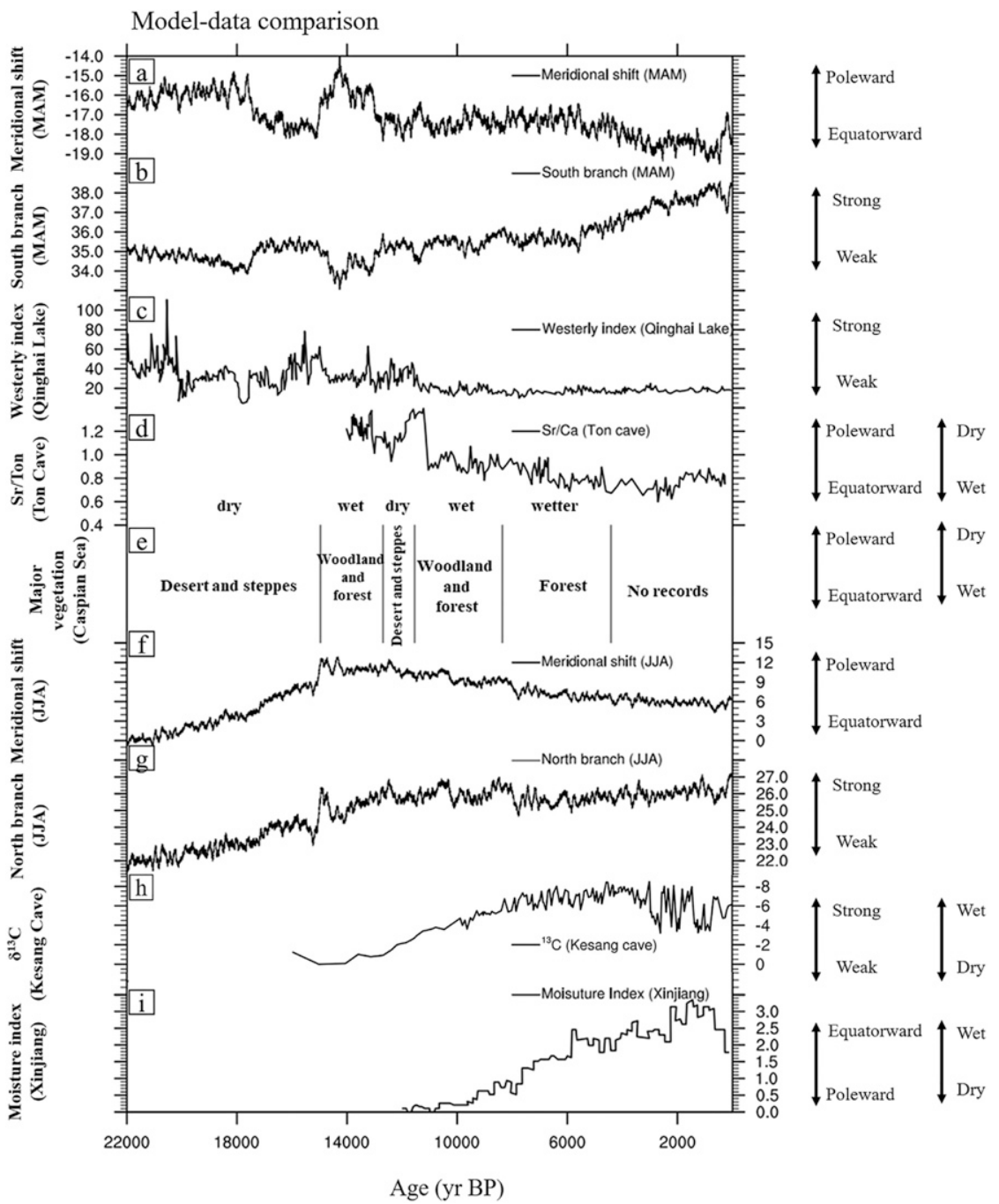

FIG. 14. (a) Evolution of the midlatitude westerlies over ACA in spring during the last $22 \mathrm{ka}$. (b) Intensity of the southern branch of the midlatitude westerlies over ACA. (c) Reconstructed westerly index based on particle sizes in Qinghai Lake (An et al. 2012). (d) Moisture evolution derived from the $\mathrm{Sr} / \mathrm{Ca}$ series from Ton Cave (Cheng et al. 2016). (e) Vegetation evolution near the Caspian Sea (Leroy et al. 2014; Zhang et al. 2018). (f) As in (a), but for the summer evolution. (g) As in (b), but for the northern branch in summer. (h) Moisture evolution derived from $\delta^{13} \mathrm{C}$ in Kesang Cave (Cheng et al. 2016). (i) Moisture evolution in Xinjiang (Wang et al. 2008; Chen et al. 2016). The northern branch is defined as zonal winds within the domain $40^{\circ}-$ $55^{\circ} \mathrm{N}, 50^{\circ}-80^{\circ} \mathrm{E}$, and the southern branch is within the domain $25^{\circ}-40^{\circ} \mathrm{N}, 50^{\circ}-80^{\circ} \mathrm{E}$.

underlying mechanisms should be further examined with additional numerical simulations in the future.

\section{b. Roles of the North Atlantic and north Indian Ocean}

Our results indicate that the shift of the midlatitude westerlies is attributed to the asymmetric change in zonal winds over ACA induced by the local anomalous cyclone/anticyclone. Generally, anomalous atmospheric circulations are maintained by the propagation of Rossby waves originating from the North Atlantic and/or diabatic heating induced by anomalous precipitation due to anomalous SST over the Indian Ocean (Fig. 13). Changes in SSTs over the North Atlantic can trigger Rossby wave trains, which alter the atmospheric circulations over ACA (Zhang et al. 2018). For the Indian Ocean, variations in SSTs change the land-sea thermal contrast, impacting the intensity of monsoons and thereby precipitation, which is generally tied to the Matsuno-Gill response (Zhao et al. 2018).

The increased greenhouse gases result in global warming by absorbing longwave radiation (Harries et al. 2001). Based on the TraCE-21ka simulations, the Indian 
Ocean seems to play a more important role in regulating the meridional shift of the midlatitude westerlies over ACA in response to variations in greenhouse gases. Such an essential role of the Indian Ocean in regulating the atmospheric circulation over ACA is also confirmed by Staubwasser and Weiss (2017), Yang et al. (2009), and Zhao et al. (2018), focusing on the Holocene, modern, and future climates under the RCP8.5 scenario, respectively. Forced by meltwater fluxes and continental ice sheets, signals from the North Atlantic broadly dominate changes in the midlatitude westerlies over ACA in both spring and summer. This is because when the meltwater fluxes increase (decrease), the AMOC weakens (intensifies) significantly, subsequently inducing HS1 and YD cooling events (BA warming) (Thornalley et al. 2010). Moreover, the AMOC damps significantly in response to the lowering of the Northern Hemisphere ice sheets (especially the Laurentide ice sheet) thereby cooling North Atlantic SSTs (Yan and Zhang 2017). Changes in SSTs and thereby atmospheric circulation through airsea interactions indicate an important role of the North Atlantic in altering the downstream westerlies. Moreover, increased insolation in summer gives rise to the warming of SSTs over the North Atlantic and Indian Oceans (Koç and Jansen 2002; Liu et al. 2006), and the North Atlantic and the Indian Oceans seem to contribute comparably in regulating the midlatitude westerlies over ACA in response to orbital insolation. However, the exact roles of the North Atlantic (e.g., the SST variations or the barotropic instability) in triggering the anomalous cyclone/ anticyclone are not deduced due to the complicated cooperating processes. In addition, the relative contributions of different oceans are hard to quantify in our study given the complex and nonlinear interactions between the atmosphere and ocean and among individual external forcings.

Notably, the amplitude of SST change is generally larger over the "high-latitude" North Atlantic than over the "low-latitude" Indian Ocean in the majority of the simulations used here. However, the larger SST anomaly over the North Atlantic does not always indicate a more important role in regulating the westerlies over ACA or suggest a potential causal relationship between the two oceans. The relative importance of the two oceans and their relationship may largely depend on the external forcings. For example, in response to elevated $\mathrm{CO}_{2}$ concentrations, our results suggest an essential role of the Indian Ocean in regulating the atmospheric circulations over ACA (Figs. 6 and 12), although the SST is much warmer over the North Atlantic. This is confirmed by the results of Yang et al. (2009) and Zhao et al. (2018), focusing on the westerlies' variations in the modern and future climates, respectively. In contrast, regarding the

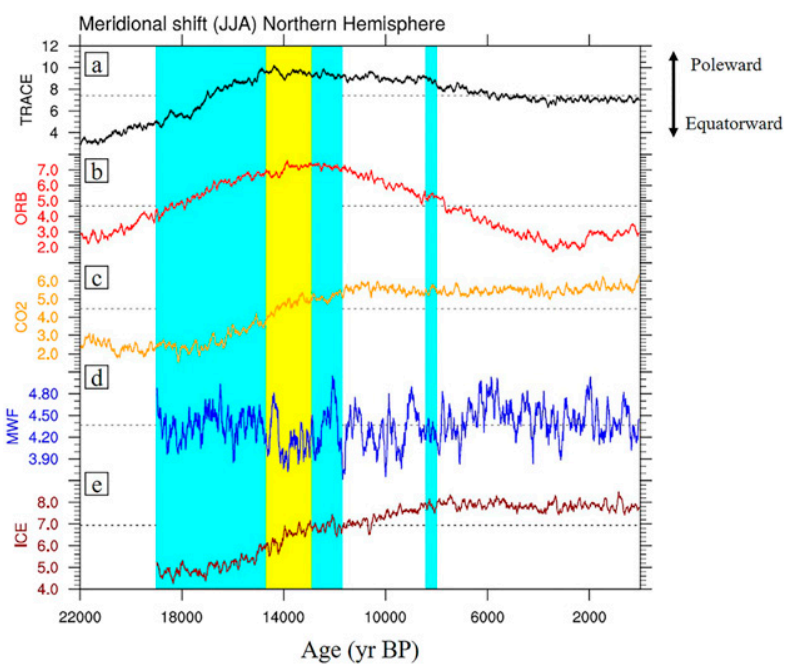

FIG. 15. Evolution of the meridional shift of the summer midlatitude westerlies over the Northern Hemisphere during the past $21 \mathrm{ka}$ in the (a) TraCE-All experiment and the experiments forced by varying only (b) orbital insolation (ORB), (c) greenhouse gas concentration $\left(\mathrm{CO}_{2}\right)$, (d) meltwater fluxes (MWF), and (e) continental ice sheets (ICE) by 101-yr smoothing. The meridional shift is obtained by the difference between zonal winds within the domains $40^{\circ}-55^{\circ}$ and $25^{\circ}-40^{\circ} \mathrm{N}$. The three cold events (Heinrich Stadial 1, Younger Dryas, and $8.2 \mathrm{ka}$ ) and the warm event (BøllingAllerød) are marked as the cyan and yellow vertical panels, respectively.

cases involving the influences of meltwater fluxes and ice sheet topography, the signal mainly comes from the North Atlantic, and the SST change over the Indian Ocean may be caused by the variation in the AMOC.

Moreover, in addition to the Matsuno-Gill response induced by the Indian Ocean, variations in heating over the Tibetan Plateau, especially in summer, may affect the geopotential height and hence the midlatitude westerlies over ACA by generating anomalous circulations with baroclinic structures (Duan et al. 2008; Wu et al. 2007) (Fig. S6). However, changes in surface heating over the TP (i.e., latent and sensible heating) are partially linked with the Indian Ocean and North Atlantic, which may regulate precipitation and temperature by altering the summer Indian monsoon and other relevant atmospheric circulations ( $\mathrm{Li}$ et al. 2005; Wu et al. 2007). Thus, it is difficult to fully separate the influences of the Indian Ocean and the TP.

\section{c. Model-data comparisons}

Previous studies suggested that the poleward (equatorward) shift of the midlatitude westerlies can result in reduced (increased) precipitation over ACA in spring and over northern Xinjiang in summer (Zhao et al. 2018). The reconstructed moisture patterns in ACA and northern Xinjiang hence provide clues to the meridional 
shift of the midlatitude westerlies in spring and summer, respectively. Additionally, several proxies (e.g., particle size) provide information on the change in the intensity of the northern or southern branches of the westerlies, which depends on where the sites are distributed. Thus, we focus on the meridional shift of the westerlies in the following comparisons together with the intensity of the southern and northern branches (Fig. 14).

Based on the loess particle sizes in Qinghai Lake $\left(36^{\circ} 32^{\prime}-37^{\circ} 15^{\prime} \mathrm{N}, 99^{\circ} 36^{\prime}-100^{\circ} 47^{\prime} \mathrm{E}\right)$, the westerlies are stronger and weaker during HS1 and BA, respectively, in spring (as the sediments are considered to be transported by the spring westerlies whose jet axis is located near the southern branch) (An et al. 2012). This is well reproduced by the TraCE-21ka simulation (i.e., the intensity of the southern branch), but the model shows little skill in depicting the stronger westerlies during the LGM. Note that the signal of the westerlies during the Holocene is very limited in this reconstruction, which may be attributed to the fact that the dominant atmospheric circulation system is not the westerlies at that time. The $\mathrm{Sr} / \mathrm{Ca}$ records in the Ton Cave $\left(38^{\circ} 24^{\prime} \mathrm{N}\right.$, $67^{\circ} 14^{\prime} \mathrm{E}$ ) suggest that ACA is relatively drier during the YD and then gets wetter during the Holocene (Cheng et al. 2016). Given that spring is the peak precipitation season over ACA, this indicates a relative poleward and equatorward shift of the midlatitude westerlies during the YD and the Holocene in spring, respectively, broadly confirmed by the model results. Additionally, the reconstructed vegetation types near the Caspian Sea indicate that conditions are drier during the LGM and BA, suggesting a poleward shift of the midlatitude westerlies in spring, while wetter conditions are identified during the HS1, YD, and the Holocene, pointing to an equatorward migration (Leroy et al. 2014; Zhang et al. 2018). These variations in the midlatitude westerlies are generally observed in the TraCE-21ka simulation.

Regarding the summer evolution, we use the $\delta^{13} \mathrm{C}$ records from Kesang Cave $\left(42^{\circ} 52^{\prime} \mathrm{N}, 81^{\circ} 45^{\prime} \mathrm{E}\right)$ documenting the local precipitation minus evaporation conditions and synthesize records of moisture changes in northern Xinjiang as proxies for the evolution of the westerlies over ACA (Chen et al. 2016; Cheng et al. 2016). It is noted that the more intense the westerlies are, the more vapor is transported (Jia et al. 2018). Hence, the intensity of the northern branch of the westerlies is taken into consideration for comparison with the $\delta^{13} \mathrm{C}$ recorded in Kesang. The $\delta^{13} \mathrm{C}$ records indicate that it has become wetter during the past $21 \mathrm{ka}$, supported by simulations in which the northern branch of the westerlies shows an intensified trend and hence more precipitation, as stronger westerlies are generally associated with enhanced water vapor transport.
Moreover, the simulated meridional shift of the westerlies is consistent with the evolution of the moisture conditions in northern Xinjiang during the Holocene (Chen et al. 2016; Wang et al. 2008). The reconstructed wetter conditions correspond to an equatorward shift of the westerlies during the early and middle Holocene, and drier conditions during the past $2 \mathrm{ka}$ are in agreement with the poleward migration. Overall, the TraCE21 ka simulations broadly capture the evolution of the meridional shift of the midlatitude westerlies in spring and summer during the past $21 \mathrm{ka}$, although model-data discrepancies still exist, which may be attributed to the uncertainties in both simulations (e.g., coarse model resolution) and reconstructions (e.g., the lack of direct proxies).

\section{d. Comparisons between ACA and the Northern Hemisphere}

Previous studies suggested the important roles of several activity centers of the midlatitude westerlies in the climate of the Northern Hemisphere $(\mathrm{NH})$ by altering the teleconnections in summer (Ding and Wang 2005). We find that the midlatitude westerlies over the $\mathrm{NH}$ are located more equatorward during the LGM, followed by a poleward shift during the last deglaciation, and then migrate equatorward during the Holocene (Fig. 15), which is also observed over ACA (Fig. 8). The meridional shift over the $\mathrm{NH}$ is also dominated by changes in orbital insolation, with positive contributions from increased greenhouse gases and reduced ice sheet topography during the last deglaciation and limited during the Holocene, and the meltwater fluxes lead to obvious oscillations near the mean state (Figs. 15b-e). The meridional shift of the midlatitude westerlies over ACA shares some similarity with the westerlies over the NH but also exhibits differences. For example, the multidecadal variability is more intense over ACA than over the $\mathrm{NH}$, and the poleward shift induced by decreased ice sheet topography is more obvious over ACA than over the NH. This may be attributed to the fact that the ACA is one of the activity centers of the summer westerlies over the NH (Ding and Wang 2005), and the behavior of the westerlies over ACA is significantly affected by the local temperature gradient. It is noted that the meridional shift of the midlatitude westerlies over ACA differs from that over the Northern Hemisphere in spring during the past $21 \mathrm{ka}$.

In addition, previous studies indicate that the summer westerly jet over West Asia $\left(35^{\circ}-50^{\circ} \mathrm{N}, 55^{\circ}-85^{\circ} \mathrm{E}\right)$ shifts equatorward in response to increased greenhouse gases (Zhao et al. 2018), as do the westerlies over the Northern Hemisphere, although the significance level varies (Grise and Polvani 2016; Son et al. 2018). In our study, the midlatitude westerlies over ACA and the $\mathrm{NH}$ both move 
poleward in summer in response to higher $\mathrm{CO}_{2}$. Such discrepancy in the migration of the westerlies may be attributed to the difference in time scales we consider. During the past $21 \mathrm{ka}$, we focus on the evolution of the westerlies on the millennial time scale (e.g., $\mathrm{CO}_{2}$ increases from 184 to 264 ppmv during 22-11 ka), whereas we focus on multidecadal to centennial time scales in future projections. This discrepancy is also seen in the variations of other climate systems. For example, Zhu et al. (2014a) noted that the AMOC generally intensifies during the past $21 \mathrm{ka}$ in response to the doubling of greenhouse gas concentrations, whereas Schmittner et al. (2005) and Weaver et al. (2007) suggested that the AMOC weakens over the next $\sim 100$ years in response to future global warming.

\section{Summary}

Based on the TraCE-21ka simulations, we provide a possible scenario for the evolution of the midlatitude westerlies over ACA during the past $21 \mathrm{ka}$ and the associated thermodynamic and dynamic mechanisms. We find that the location of the midlatitude westerlies over ACA oscillates largely in spring during the last deglaciation, whereas it gradually moves poleward in summer. During the Holocene, the midlatitude westerlies exhibit a long-term equatorward trend in both seasons. The estimated meridional shift of the midlatitude westerlies over ACA is generally consistent with geological evidence.

Moreover, the dominant driving factors vary with time and across seasons. In spring, the variation in the midlatitude westerlies over ACA is primarily regulated by meltwater fluxes and continental ice sheets during the last deglaciation. The westerlies shift poleward (equatorward) arising from the reduced (enhanced) meltwater fluxes. In response to the lowering of the continental ice sheets, the midlatitude westerlies over ACA broadly move poleward. Additionally, orbital insolation drives the equatorward shift of the midlatitude westerlies over ACA during the Holocene. In summer, the long-term trend of the meridional shift of the midlatitude westerlies over ACA is controlled by orbital insolation during the past $21 \mathrm{ka}$.

Although uncertainties in both simulations (e.g., coarse model resolution) and reconstructions (e.g., the lack of direct proxies) exist, our study places the midlatitude westerlies over ACA in a long-term paleoclimate context and provides a testable response of the westerlies to the various external forcings. This may be a reference for the climate projection for a future warmer world induced by increased greenhouse gases with the potential melting of the Greenland ice sheet. In addition, we highlight the important roles of both the Indian
Ocean and the North Atlantic Ocean in regulating the westerlies. These results may shed light on the behavior of the westerlies in the long-term future and hence have important implications for predicting precipitation over ACA.

Acknowledgments. Many thanks to the three anonymous reviewers for their very constructive and useful comments in helping to improve our manuscript. We thank the TraCE-21ka group for sharing their model output via the Earth System Grid of the National Center for Atmospheric Research. The model data are available online (https://www.earthsystemgrid.org/project/trace. $\mathrm{html}$ ). This research was supported by the Strategic Priority Research Program of the Chinese Academy of Sciences (XDA20070103), the Youth Innovation Promotion Association by CAS (2019080), and the Young Elite Scientists Sponsorship Program by CAST (2017QNRC001).

\section{REFERENCES}

Ambrizzi, T., B. J. Hoskins, and H. Hsu, 1995: Rossby wave propagation and teleconnection patterns in the austral winter. J. Atmos. Sci., 52, 3661-3672, https://doi.org/10.1175/15200469(1995)052<3661:RWPATP>2.0.CO;2.

An, Z., and Coauthors, 2012: Interplay between the westerlies and Asian monsoon recorded in Lake Qinghai sediments since 32 ka. Sci. Rep., 2, 619, https://doi.org/10.1038/srep00619.

Benestad, R. E., 2005: Climate change scenarios for northern Europe from multi-model IPCC AR4 climate simulations. Geophys. Res. Lett., 32, L17704, https://doi.org/10.1029/2005GL023401.

Bromwich, D. H., E. R. Toracinta, H. Wei, J. L. Fastook, and T. J. Hughes, 2004: Polar MM5 simulations of the winter climate of the Laurentide Ice Sheet at the LGM. J. Climate, 17, 3415-3433, https:// doi.org/10.1175/1520-0442(2004)017<3415:PMSOTW>2.0.CO;2.

Chen, F., and Coauthors, 2008: Holocene moisture evolution in arid central Asia and its out-of-phase relationship with Asian monsoon history. Quat. Sci. Rev., 27, 351-364, https://doi.org/ 10.1016/j.quascirev.2007.10.017.

_ W. Wuang, L. Jin, J. Chen, and J. Wang, 2011: Spatiotemporal precipitation variations in the arid Central Asia in the context of global warming. Sci. China Earth Sci., 54, 1812-1821, https:// doi.org/10.1007/s11430-011-4333-8.

—_ and Coauthors, 2016: A persistent Holocene wetting trend in arid central Asia, with wettest conditions in the late Holocene, revealed by multi-proxy analyses of loess-paleosol sequences in Xinjiang, China. Quat. Sci. Rev., 146, 134-146, https:// doi.org/10.1016/j.quascirev.2016.06.002.

_ Spatiotemporal differences in climate change and possible mechanisms on decadal to sub-orbital timescales. Earth-Sci. Rev., 192, 337-354, https://doi.org/10.1016/j.earscirev.2019.03.005.

Chen, X., S. Wang, Z. Hu, Q. Zhou, and Q. Hu, 2018: Spatiotemporal characteristics of seasonal precipitation and their relationships with ENSO in Central Asia during 1901-2013. J. Geogr. Sci., 28, 1341-1368, https://doi.org/10.1007/s11442-018-1529-2.

Cheng, H., and Coauthors, 2016: Climate variations of Central Asia on orbital to millennial timescales. Sci. Rep., 6, 36975, https:// doi.org/10.1038/srep36975. 
Christie, A. M., S. J. Lilley, E. Staunton, Y. G. Andreev, and P. G. Bruce, 2005: Increasing the conductivity of crystalline polymer electrolytes. Nature, 433, 50-53, https://doi.org/ 10.1038/nature03186.

Ding, Q., and B. Wang, 2005: Circumglobal teleconnection in the Northern Hemisphere summer. J. Climate, 18, 3483-3505, https://doi.org/10.1175/JCLI3473.1.

Duan, A., G. Wu, and X. Liang, 2008: Influence of the Tibetan Plateau on the summer climate patterns over Asia in the IAP/ LASG SAMIL model. Adv. Atmos. Sci., 25, 518-528, https:// doi.org/10.1007/s00376-008-0518-2.

Gill, A. E., 1980: Some simple solutions for heat-induced tropical circulation. Quart. J. Roy. Meteor. Soc., 106, 447-462, https:// doi.org/10.1002/qj.49710644905.

Golledge, N. R., E. D. Keller, N. Gomez, K. A. Naughten, J. Bernales, L. D. Trusel, and T. L. Edwards, 2019: Global environmental consequences of twenty-first-century ice-sheet melt. Nature, 566, 65-72, https://doi.org/10.1038/s41586-0190889-9.

Grise, K. M., and L. M. Polvani, 2016: Is climate sensitivity related to dynamical sensitivity? J. Geophys. Res. Atmos., 121, 51595176, https://doi.org/10.1002/2015JD024687.

Harries, J. E., H. E. Brindley, P. J. Sagoo, and R. J. Bantges, 2001: Increases in greenhouse forcing inferred from the outgoing longwave radiation spectra of the Earth in 1970 and 1997. Nature, 410, 355-357, https://doi.org/10.1038/35066553.

He, F., 2011: Simulating transient climate evolution of the last deglaciation with CCSM3. Ph.D. thesis, University of WisconsinMadison, $161 \mathrm{pp}$

, J. D. Shakun, P. U. Clark, A. E. Carlson, Z. Liu, B. L. OttoBliesner, and J. E. Kutzbach, 2013: Northern Hemisphere forcing of Southern Hemisphere climate during the last deglaciation. Nature, 494, 81-85, https://doi.org/10.1038/nature11822.

Hong, X., R. Lu, and S. Li, 2018: Asymmetric relationship between the meridional displacement of the Asian westerly jet and the Silk Road pattern. Adv. Atmos. Sci., 35, 389-396, https:// doi.org/10.1007/s00376-017-6320-2.

Hsu, H.-H., and X. Liu, 2003: Relationship between the Tibetan Plateau heating and East Asian summer monsoon rainfall. Geophys. Res. Lett., 30, 2066, https://doi.org/10.1029/2003GL017909.

Huang, J., H. Yu, A. Dai, Y. Wei, and L. Kang, 2017: Drylands face potential threat under $2^{\circ} \mathrm{C}$ global warming target. Nat. Climate Change, 7, 417-422, https://doi.org/10.1038/nclimate3275.

Huang, W., F. Chen, S. Feng, J. Chen, and X. Zhang, 2013: Interannual precipitation variations in the mid-latitude Asia and their association with large-scale atmospheric circulation. Chin. Sci. Bull., 58, 3962-3968, https://doi.org/10.1007/s11434013-5970-4.

_ J. Chen, X. Zhang, S. Feng, and F. Chen, 2015: Definition of the core zone of the "westerlies-dominated climatic regime", and its controlling factors during the instrumental period. Sci. China Earth Sci., 58, 676-684, https://doi.org/10.1007/s11430015-5057-y.

Jia, J., H. Liu, F. Gao, and D. Xia, 2018: Variations in the westerlies in Central Asia since 16 ka recorded by a loess section from the Tien Shan Mountains. Palaeogeogr. Palaeoclimatol. Palaeoecol., 504, 156-161, https://doi.org/10.1016/j.palaeo.2018.05.021.

Koç, N., and E. Jansen, 2002: Holocene climate evolution of the North Atlantic Ocean and the Nordic Seas-A synthesis of new results. Climate Development and History of the North Atlantic Realm, E. Jansen et al., Eds., Springer, 165-173.

Kong, W., L. M. Swenson, and J. C. H. Chiang, 2017: Seasonal transitions and the westerly jet in the Holocene East Asian summer monsoon. J. Climate, 30, 3343-3365, https://doi.org/ 10.1175/JCLI-D-16-0087.1.

Leroy, S. A. G., L. López-Merino, A. Tudryn, F. Chalié, and F. Gasse, 2014: Late Pleistocene and Holocene palaeoenvironments in and around the middle Caspian basin as reconstructed from a deepsea core. Quat. Sci. Rev., 101, 91-110, https://doi.org/10.1016/ j.quascirev.2014.07.011.

Li, J., R. Yu, T. Zhou, and B. Wang, 2005: Why is there an early spring cooling shift downstream of the Tibetan Plateau? J. Climate, 18, 4660-4668, https://doi.org/10.1175/JCLI3568.1.

Li, X., D. Jiang, Z. Zhang, R. Zhang, Z. Tian, and Q. Yan, 2015: Mid-Pliocene westerlies from PlioMIP simulations. $A d v$. Atmos. Sci., 32, 909-923, https://doi.org/10.1007/s00376-0144171-7.

Li, Y., Y. Song, Q. Yin, L. Han, and Y. Wang, 2019: Orbital and millennial northern mid-latitude westerlies over the last glacial period. Climate Dyn., 53, 3315-3324, https://doi.org/ 10.1007/s00382-019-04704-5.

Liu, X., Z. Liu, J. E. Kutzbach, S. C. Clemens, and W. L. Prell, 2006: Hemispheric insolation forcing of the Indian Ocean and Asian monsoon: Local versus remote impacts. J. Climate, 19, 61956208, https://doi.org/10.1175/JCLI3965.1.

Liu, Z., and Coauthors, 2009: Transient simulation of last deglaciation with a new mechanism for Bølling-Allerød warming science. Science, 325, 310-314, https://doi.org/10.1126/SCIENCE.1171041.

- Z. Lu, X. Wen, B. L. Otto-Bliesner, A. Timmermann, and K. M. Cobb, 2014: Evolution and forcing mechanisms of El Niño over the past 21,000 years. Nature, 515, 550-553, https:// doi.org/10.1038/nature13963.

Lu, R., 2004: Associations among the components of the East Asian summer monsoon system in the meridional direction. J. Meteor. Soc. Japan, 82, 155-165, https://doi.org/10.2151/ jmsj.82.155.

, H. Ye, and J.-G. Jhun, 2011: Weakening of interannual variability in the summer East Asian upper-tropospheric westerly jet since the mid-1990s. Adv. Atmos. Sci., 28, 1246-1258, https://doi.org/10.1007/s00376-011-0222-5.

Mason, S. J., and L. Goddard, 2001: Probabilistic precipitation anomaliesassociated with ENSO. Bull. Amer. Meteor. Soc., 82, 619-638, https://doi.org/10.1175/1520-0477(2001)082<0619: PPAAWE $>2.3 . \mathrm{CO} ; 2$

Matsuno, T., 1966: Quasi-geostrophic motions in the equatorial area. J. Meteor. Soc. Japan, 44, 25-43, https://doi.org/10.2151/ jmsj1965.44.1_25.

Rojas, M., and Coauthors, 2009: The southern westerlies during the last glacial maximum in PMIP2 simulations. Climate Dyn., 32, 525-548, https://doi.org/10.1007/s00382-008-0421-7.

Schmittner, A., M. Latif, and B. Schneider, 2005: Model projections of the North Atlantic thermohaline circulation for the 21st century assessed by observations. Geophys. Res. Lett., 32, L23710, https://doi.org/10.1029/2005GL024368.

Shi, J., and Q. Yan, 2019: Evolution of the Asian-African monsoonal precipitation over the last $21 \mathrm{kyr}$ and the associated dynamic mechanisms. J. Climate, 32, 6551-6569, https:// doi.org/10.1175/JCLI-D-19-0074.1.

Son, S.-W., S.-Y. Kim, and S.-K. Min, 2018: Widening of the Hadley cell from Last Glacial Maximum to future climate. J. Climate, 31, 267-281, https://doi.org/10.1175/JCLI-D-17-0328.1.

Staubwasser, M., and H. Weiss, 2017: Holocene climate and cultural evolution in late prehistoric-early historic West Asia. Quat. Res., 66, 372-387, https://doi.org/10.1016/j.yqres.2006.09.001.

Takaya, K., and H. Nakamura, 2001: A formulation of a phaseindependent wave-activity flux for stationary and migratory 
quasigeostrophic eddies on a zonally varying basic flow. J. Atmos. Sci., 58, 608-627, https://doi.org/10.1175/1520-0469(2001) $058<0608$ :AFOAPI $>2.0 . \mathrm{CO} ; 2$.

Thornalley, D. J. R., I. N. McCave, and H. Elderfield, 2010: Freshwater input and abrupt deglacial climate change in the North Atlantic. Paleoceanography, 25, PA1201, https:/doi. org/10.1029/2009PA001772.

Toggweiler, J. R., J. L. Russell, and S. R. Carson, 2006: Midlatitude westerlies, atmospheric $\mathrm{CO}_{2}$, and climate change during the ice ages. Paleoceanography, 21, PA2005, https://doi.org/10. 1029/2005PA001154.

Wang, N., D. Jiang, and X. Lang, 2018: Northern westerlies during the Last Glacial Maximum: Results from CMIP5 simulations. J. Climate, 31, 1135-1153, https://doi.org/10.1175/JCLI-D-170314.1.

Wang, Y., and Coauthors, 2008: Millennial- and orbital-scale changes in the East Asian monsoon over the past 224,000 years. Nature, 451, 1090-1093, https://doi.org/10.1038/nature06692.

Weaver, A. J., M. Eby, M. Kienast, and O. A. Saenko, 2007: Response of the Atlantic meridional overturning circulation to increasing atmospheric $\mathrm{CO}_{2}$ : Sensitivity to mean climate state. Geophys. Res. Lett., 34, L05708, https://doi.org/10.1029/ 2006 GL028756.

Wei, Y., H. Yu, J. Huang, T. Zhou, M. Zhang, and Y. Ren, 2019: Drylands climate response to transient and stabilized $2{ }^{\circ} \mathrm{C}$ and $1.5^{\circ} \mathrm{C}$ global warming targets. Climate Dyn., 53, 2375-2389, https://doi.org/10.1007/s00382-019-04860-8.

Wen, X., Z. Liu, S. Wang, J. Cheng, and J. Zhu, 2016: Correlation and anti-correlation of the East Asian summer and winter monsoons during the last 21,000 years. Nat. Commun., 7, 11999, https://doi.org/10.1038/ncomms11999.

Wilcox, L. J., A. J. Charlton-Perez, and L. J. Gray, 2012: Trends in austral jet position in ensembles of high- and low-top CMIP5 models. J. Geophys. Res., 117, D13115, https://doi.org/10.1029/ 2012JD017597.
Wilks, D. S., 1995: Statistical Methods in the Atmospheric Sciences: An Introduction. Academic Press, $467 \mathrm{pp}$.

Wu, G., and Coauthors, 2007: The influence of mechanical and thermal forcing by the Tibetan Plateau on Asian climate. J. Hydrometeor., 8, 770-789, https://doi.org/10.1175/JHM609.1.

Yan, Q., and Z. Zhang, 2017: Dominating roles of ice sheets and insolation in variation of tropical cyclone genesis potential over the North Atlantic during the last 21,000 years. Geophys. Res. Lett., 44, 10 624-10 632, https://doi.org/10.1002/2017GL075786.

Yang, J., Q. Liu, Z. Liu, L. Wu, and F. Huang, 2009: Basin mode of Indian Ocean sea surface temperature and Northern Hemisphere circumglobal teleconnection. Geophys. Res. Lett., 36, L19705, https://doi.org/10.1029/2009GL039559.

Yang, S., K.-M. Lau, and K.-M. Kim, 2002: Variations of the East Asian jet stream and Asian-Pacific-American winter climate anomalies. J. Climate, 15, 306-325, https://doi.org/10.1175/ 1520-0442(2002)015<0306:VOTEAJ>2.0.CO;2.

Yeager, S. G., C. A. Shields, W. G. Large, and J. J. Hack, 2006: The low-resolution CCSM3. J. Climate, 19, 2545-2566, https:// doi.org/10.1175/JCLI3744.1.

Zhang, X., J. Li, M. Gao, and L. Jin, 2018: Simulated precipitation changes in Central Asia since the Last Glacial Maximum. Quat. Int., 490, 82-97, https://doi.org/10.1016/j.quaint.2018.05.007.

Zhao, Y., X. Yu, J. Yao, and X. Dong, 2018: Evaluation of the subtropical westerly jet and its effects on the projected summer rainfall over central Asia using multi-CMIP5 models. Int. J. Climatol., 38, e1176-e1189, https://doi.org/10.1002/joc.5443.

Zhu, J., Z. Liu, J. Zhang, and W. Liu, 2014a: AMOC response to global warming: Dependence on the background climate and response timescale. Climate Dyn., 44, 3449-3468, https:// doi.org/10.1007/s00382-014-2165-x.

,,-- X. Zhang, I. Eisenman, and W. Liu, 2014b: Linear weakening of the AMOC in response to receding glacial ice sheets in CCSM3. Geophys. Res. Lett., 41, 6252-6258, https:// doi.org/10.1002/2014GL060891. 